\title{
HIGH YIELDS: THE SPREAD ON GERMAN INTEREST RATES
}

\author{
Carlo Favero \\ Francesco Giavazzi \\ Luigi Spaventa
}

Working Paper 5408

\section{NATIONAL BUREAU OF ECONOMIC RESEARCH 1050 Massachusetts Avenue \\ Cambridge, MA 02138 \\ January 1996}

We thank Stefan Gerlach and participants in the 1995 CEPR International Macroeconomics Workshops for many useful comments. Alessandro Missale, Salvatore Biasco and Juan Dolado also provided us with extended comments, as did Vittorio Conti, Fabio Innocenti and Mario Noera. We are grateful to Marco Mazzucchelli and Roberto Hoornweg of Morgan Stanley International for providing us with a time series of the cost of guaranteed reimbursement of the withholding tax on Italian government bonds. All the remaining data used in this paper have been retrieved from the Datastream Online Service. Pierpaolo Benigno and Marco Pifferi provided creative and efficient research assistance. This paper is part of NBER's research program in International Finance and Macroeconomics. Any opinions expressed are those of the authors and not those of the National Bureau of Economic Research.

() 1996 by Carlo Favero, Francesco Giavazzi and Luigi Spaventa. All rights reserved. Short sections of text, not to exceed two paragraphs, may be quoted without explicit permission provided that full credit, including $(\mathcal{C}$ notice, is given to the source. 


\title{
HIGH YIELDS: THE SPREAD ON \\ GERMAN INTEREST RATES
}

\begin{abstract}
This paper is a first attempt at evaluating the determinants of the total interest rate differentials on government bonds between high yielders, namely Italy, Spain, Sweden and Germany. In particular we address the question of the relative importance of local and global factors in the determination of such spreads. We identify and measure two components of total yield differentials: one due to expectations of exchange rate depreciation -- which we call the exchange rate factor -- another which reflects the market assessment of default risk. We propose and discuss a measure of the exchange rate factors and of the default risk premium based on interest rate swaps.

Overall our investigation provides strong evidence in favor of the existence of a common trend for the Italian and Spanish spreads on Bunds, which is not shared by the Swedish spread. Such a trend is driven by international factors and is independent from country-specific shocks. Country-specific shocks are only relevant in explaining short term cycles around the common stochastic trend.

Carlo Favero

Department of Economics

Universita L. Bocconi

Via Gobbi 5

20136 Milano

ITALY

Francesco Giavazzi

Department of Economics

Università L. Bocconi

Via Gobbi 5

20136 Milano

ITALY

and NBER
\end{abstract}

\section{Luigi Spaventa}

Dipartimento di Scienze Economiche

Università degli studi di Roma

Via G.B. de Rossi 29

00161 Roma

ITALY 


\section{Introduction}

The globalization of financial markets and the rapid growth of public debt in many countries has resulted in the market for government bonds becoming the most important segment of international financial markets. More than ever before, yield differentials between government bonds issued by different states reflect the assessment and the sentiments of market participants regarding countries' short and long term financial prospects. Therefore, such differentials are immediately affected by news, are carefully watched in search for arbitrage opportunities, are considered by governments and monetary authorities as a signal of credibility of their policies and as a measure of expectations. More recently yield differentials have acquired a specific policy relevance with the Maastricht Treaty. The Protocol on the convergence for eligibility to the Economic and Monetary Union (set in article 109J) stipulates that the long-term nominal interest rate on bonds issued by a member State should not exceed -- on average over the year preceding the beginning of stage three of EMU -- by more than two-hundred basis point those in the three best performing members in terms of price stability.

In Europe, yield spreads are measured in terms of differences of annualised interest rates with respect to Germany: German yields have been and are the lowest on all maturities and German bonds provide the yardstick of a risk-free asset. Yield spreads fluctuate over time, and the observation of their behaviour over the last four years (shown in Figure 1) reveals two interesting features.

- European countries can be grouped in two classes: high yielders -- Italy, Spain and, lately, Sweden - featuring high and volatile spreads on German interest rates; and low yielders, featuring low and relatively stable spreads on German interest rates.

- Yield spreads do not show a stable relation with the inflation differentials between European countries and Germany and, more generally, high-yielders feature very different fundamentals.

In this paper we concentrate on high-yielders and try to understand the fluctuations of the spreads over Bunds. In particular we address the question of the relative importance of local and global factors in the determination of such spreads. In other words, do spreads for high-yielders react to common factors, independently of country-specific fundamentals, or are country-specific factors relevant in the determination of some portfolio diversification among high yielders?

To address this question we shall first consider the possible determinants of spreads on government bonds issued by "high yielders" and deal with measurement problems. We then discuss the results of an empirical analysis designed to investigate how these determinants affect the spread over time and how they interact with each other. 


\section{The determinants of yield differentials and their measure}

The existence of a spread between the yields on government bonds issued by different states and denominated in different currencies is usually attributed to an exchange rate factor and to a "default" risk factor. The former reflects the expectations of currency depreciation (plus a linearization term and a foreign exchange rate risk premium (see, for example, Ayuso and Restoy,1995). The definition of default risk is more vague. It captures the fear that something may sooner or later go wrong with the service of the debt: outright default on debt service; rescheduling and consolidation of shorter term bonds; delays in the payment of interest. The perception of such risk may arise out of the sheer size of a country's debt, which makes stabilisation an uphill job; or, even when stabilisation is feasible, it may be due to political instability which delays the required adjustment, or to a negative assessment of domestic fiscal policies which are projected to cause a debt explosion in the future. Given the very different dynamics of the government budgetary position among high yielders, we feel that some measure of default risk could be helpful towards the aim of separating local from global factors affecting the total spreads for these countries.

In this section we start by showing that the correct decomposition of the total spread in the sum of an exchange risk factor and a default risk factor requires the use of continuously compounded yields. We shall then discuss the choice of different possible measures of the default risk. After a first inspection of the evidence we shall consider the complications introduced by international differences in the tax treatment of interest payments.

\section{An exact decomposition of total yield differentials}

Consider the uncovered interest rate parity condition between two assets, denominated, respectively, in $D$-marks and in another currency: currency $j$. For the time being we shall assume that these assets are not affected by default risk. Neglecting the foreign exchange risk premium, the arbitrage condition is:

$$
\left(1+i s_{j, t, T}\right)=\left(1+i s_{g, t, T}\right)\left(\frac{E_{t} S_{t+T}}{S_{t}}\right)^{1 / T}
$$

where, $i s_{j, t, T}$ and $i s_{g, t} T$ are the annualised yields on assets free of default risk issued at time $t$ and maturing at $t+T$ denominated, respectively, in currency $j$ and in D-marks. $E_{t} S_{t+T}$ is the expectation for the exchange rate formed at time $t$ for time $t+T$. (See Svensson, 1991)

Defining the exchange rate factor as:

$$
e_{j, t, T} \equiv\left(\frac{E_{t} S_{t+T}}{S_{t}}\right)^{1 / T}-1
$$

we can rewrite (1) as:

$$
\left(1+i s_{j, t, T}\right)=\left(1+i s_{g, t, T}\right)\left(1+e r_{j, t, T}\right)
$$

and the spread as:

$$
\left(\text { is }_{j, t, T}-i s_{g, t, T}\right)=\left(1+i s_{g, t, T}\right) e r_{j, t, T}
$$


Equation (4) shows that the simple difference between annualised rates is affected by the level of the German interest rate. For a given exchange rate factor, the spread defined on annualised rates widens as the level of German interest rates rises.

Let us now introduce default risk. Let $\mathrm{p}$ be the probability that something unpleasant may happen to debt service before $T$ in country $j$, and let $\alpha$ be the cost for the creditor of the borrower's decision leading to that outcome. The arbitrage condition between country j's government bonds and German government bonds now requires:

$$
\left(1+i_{j, t, T}\right)(1-p)+p(1-\alpha)\left(1+i_{j, t, T}\right)=\left(1+i_{g, t, T}\right)\left(\frac{E_{t} S_{t+T}}{S_{t}}\right)^{l / T}
$$

where $i_{j, L, T}$ is the annualised yield on a government bond issued by country $j$. Substituting (4) into (5) the arbitrage condition may be rewritten as:

$$
\left(1+i_{j, t, T}\right)(1-\alpha p)=\left(1+i_{g, t, T}\right) \frac{\left(1+i s_{j, t, T}\right)}{\left(1+i s_{g, t, T}\right)}
$$

Define now a measure of the incidence of default perceived at time $t$ for a bond issued by country $j$, with $T$ years to maturity:

$$
d_{j, t, I} \equiv \frac{\alpha p}{1-\alpha p}
$$

where $d$ varies from zero (when either $\alpha$ or $p$ is zero) to infinity (when both $\alpha$ and $p$ are one). The arbitrage condition (6) can now be re-written as:

$$
\frac{\left(1+i_{j, t, T}\right)}{\left(1+i_{g, t, T}\right)}=\left(1+d_{j, t, T}\right) \frac{\left(1+i s_{j, t, T}\right)}{\left(1+i s_{g, t, T}\right)}
$$

which decomposes the ratio of total yield differentials into a default risk premium and an exchange rate factor.

Taking the logs of both sides of (8) and noting that the logs of one plus the annual compounded interest rates are the continuously compounded interest rates, we have:

$$
S P_{j, t, T}=D R_{j, t, T}+E R_{j, t, T}
$$

where:

$$
\begin{aligned}
& D_{j, t, T} \equiv \log \left(1+d_{j, t, T}\right) \\
& E_{j, t, T} \equiv I S_{j, t, T}-I S_{g, t, T}=\log \left(1+i s_{j, t, T}\right)-\log \left(1+i s_{g, t, T}\right)
\end{aligned}
$$

$\mathrm{SP}_{\mathrm{j}, \mathrm{LT}}$ is the continuously compounded yield differential, at time $\mathrm{t}$, between government bonds with residual life $T$ issued by the $j$ country and by Germany, $E R_{j, L T}$ is the continuously compounded exchange risk, and $D R_{, L T}$ is the continuously compounded measure of default risk premium perceived at $t$ for the $\mathrm{j}$-country government bonds with residual life $\mathrm{T}$. Note that the decomposition defined on 
continuously compounded rates is exact and the dependence of the yield differential on the level of German interest rates disappears when continuously compounded rates rather than annually compounded rates are considered.

Equation (9) shows that an exact decomposition of the total yield spread as a sum of an exchange risk factor and a country, or default risk factor requires that the variables be converted from annualised to continuously compounded rates. This is what we shall do in what follows.

\section{Measures}

Given the total yield spread SP, the choice is between using an independent measure of the exchange rate risk, ER, thus treating the default risk as a residual, and using an independent measure of the default risk, $\mathrm{DR}$, treating the exchange rate risk as a residual.

Considering first ER, in principle a "pure" measure of expected exchange rate changes could be provided by a comparison of the yields of assets denominated in two different currencies (say, one in Italian lire, the other in D-marks) and with the same life to maturity issued by the same (nongovernment) subject, or by two otherwise identical issuers. Candidates for this measure are

- long-term bonds issued by the same supra-national organisation (such as the World Bank or the European Investment Bank) in different currencies;

- the fixed interest rates on swap contracts denominated in different currencies.

Supra-national issues are by definition free of any specific default risk. As for interest rate swaps, their market is not regulated and there is not a standard contract. The contract usually consists of an agreement to exchange two flows of interest payments: one at a fixed rate for one at a floating rate (usually the six-month LIBOR rate). A swap contract differs from a position in government bonds in that there are events to which the LIBOR rate reacts differently from the interest rate on government bonds. While the difference between the two positions should be negligible in the case of an outright default and a full-fledged financial crisis (in which case the LIBOR rate should shoot to infinity as the interest rate on government bonds), the LIBOR rate is likely to be much less affected in cases of rescheduling and partial consolidation of shorter term bonds or delays in the payment of interest. Figure 2.1 shows the yield differential between two 1993-2003 IBRD (World Bank) issues denominated in Italian lire and D-marks. Figure 2.2 reports the swaps-based measure of the exchange rate factor.

The first measure, though attractive, has several drawbacks. The market for bonds issued by supra-national organisations is far less liquid and deep than that for government bonds, and yield differentials may therefore reflect differences in the width of the bid-ask spread. More importantly, supra-national issues in some currencies are intermittent, while yield differentials on government bonds are always computed on the latest issues of the benchmarks (those "on the run"). There may however be problems also with the swap rate differentials, as they may be affected by the emergence of financial difficulties of the banking sector in one country. On balance, however, we believe that the drawbacks of the interest differential on supranational issues are greater, and we shall therefore use the spread on fixed interest rate swap contracts as an indicator of the exchange rate determinant of the yield spread on government bonds. Moreover, whereas IBRD normally issues 10-year bonds, interest rates on swap contracts are available for every maturity, thus allowing to examine the behaviour of the exchange-rate component of the total spread between government bonds at different maturities.

We thus define 


$$
E R_{j, L T}=I S_{j, L T}-I S_{g, T}
$$

as an independent measure of the exchange rate risk, where the two terms on the right-hand side are the continuously compounded fixed interest rates on swap contracts respectively in the $j$ and the $g$ currency.

Coming now to the default risk term, an independent measure could be found by comparing the yields of bonds issued in the same currency by country $\mathrm{j}$ and by a different sovereign issuer. In this vein, Giovannini and Piga (1991) used the yield differential between two dollar denominated bonds: one issued by the Republic of Italy and one, of roughly the same maturity; issued by the World Bank (or by the US Treasury). Before them, Cottarelli and Mecagni (1990) found that the yield on Italian government bonds was higher than that on similar lira bonds issued by Italian medium-term credit institutions and took this difference as a measure of the risk perceived on Italian government bonds. The two measures of default premia are reported in figures 3.1 and 3.2 .

These measures are, in our view, unsatisfactory, for both empirical and technical reasons. Just as supranational issues, the issues by the Republic of Italy on the global or on the Euro-syndicated market are not very liquid, as they are held by long-term investors, including central banks, are not the object of short-term arbitrage trading, are intermittent in time and do not cover all relevant maturities. Bonds issued by Italian credit institutions, are hardly traded in exchanges, and are even less liquid. More importantly, perhaps, in foreign borrowing -- especially on issues in the "global" market -- legal guarantees for creditors are stipulated which are non-existent for domestic bonds (in the case of global issues in the United States, for instance, a US court is competent in the case of litigation).

These strictures do not apply to another independent measure of default risk, often used by practitioners $^{1}$. If domestic sovereign bonds were risk-free assets, their yield should be lower than, or at most equal to, the fixed rate on swap contracts, stipulated in the same currency and of equal maturity, between two private parties. The latter is a good term of comparison, as the swap market is liquid, rates are quoted every day and contracts cover the relevant maturities. The excess of the yield of govermment bonds on the fixed rate of swap contracts of the same maturity could thus be taken as a reliable independent measure of the default risk premium. There is however another drawback: if, as is always the case, German government bond rates are lower than the corresponding D-mark swap rates, such measure will underestimate the risk perceived on country j's government bonds relative to German government bonds (and overestimate, as a result, the exchange risk component),

Therefore, consistently with our choice to use the yield differential on swap contracts as an independent measure of the exchange rate risk, we treat default risk as a residual, and posit:

$$
D R_{j, t . T}=S P_{j, t, T}-E R_{j, t, T}=\left(I_{j, t . T}-I S_{j, t . T}\right)-\left(I_{g . t . T}-I S_{g, t . T}\right)
$$

as the continuously compounded measure of default risk premium perceived at $t$ for the $j$-country government bonds with residual life $T{ }^{2}$ A positive value of $D R$ therefore reflects a different behaviour of the differential between government bonds and swaps relative to the reference case. We take Germany as our reference country with zero default risk by assumption. DR is reported for Italy in

\footnotetext{
'See also Banca d'Italia, Bollettino Economico,no. 23, October 1994

2 An equivalent measure was first considered in Centro Europa Ricerche. Rapporto, 1, 1995, where the spread of an IBRD bond denonominanted in Italian lire on an equivalent IBRD D-Mark bond was used. The difference between the government bond spread and the swap spread. computed on annually compounded interest rates, is now used by the Bank of Italy: see Banca d'Italia, Bollettino Economico, n.24, February 1995 and Bollettino Economico, n 25, October 1995
} 
figure 3.3. The comparison of the swaps' based measure with the Giovannini-Piga measure confirms that the latter is on average smaller in size, and especially far less volatile: there are periods when it hardly moves, while ours increases steeply -- an indirect evidence that the market for foreign issues of the Republic of Italy is somehow insulated from the gyrations of the wider bond market, and a proof that the use of the spread of the Republic's foreign issues as an independent measure of the default risk would lead an unwarranted overvaluation of the effects of exchange rate expectations.

\section{The data}

Figures 4.1-4.3 and 5.1-5.3 show the total yield spread of Italian, Spanish and Swedish government bonds over German bonds for, respectively, 10 and 3-years maturities from the beginning of 1992 until October 1995. We consider continuously compounded interest rates, obtained by taking logarithms of one plus the yearly compounded redemption yields ${ }^{3}$. All the original rates are defined consistently according to the international bond standard (30/360). All statistical results are based on the sample January 1993-October 1995 The same figures also show the exchange-rate risk component of the spread, measured as in (10).

It is readily seen that the exchange-rate component normally exceeds, though by little, the total yield spread in the case of Sweden, it is at times slightly lower in the case of Spain, whereas it is consistently lower in the case of Italy. Hence the default risk, measured as in (11), is consistently positive in the case of Italy, slightly positive, but on average not far from zero, in the case of Spain, almost always negative in the case of Sweden. This is better shown in figures 4.1-4.3 for the 10-year maturity (the figures for the 3-year maturity confirm this general observation).

These data raise a number of issues. We shall address five in particular: (i) Are the three series of total yield differentials for three high-yielders, Spain, Sweden and Italy, driven by a common trend? (ii) Considering that Sweden has never belonged to the exchange-rate mechanism of the EMS and that Italy abandoned it in September 1992, while Spain has always remained in the mechanism, does the perception of an exchange-rate risk for the three currencies reflect this difference of regime? (iii) What can we say on the maturity structure of the yield differentials and of their components? (iv) What are the international and country-specific determinants of the total yield differential ? (v) Finally, what is the dynamic response of interest rate spreads to shocks?

Before attempting to answer these questions, however, we must consider whether, and to what extent, the data reported in our figures are biased by differences in the tax treatment of interest payments in the countries concerned. The problem, as we shall see presently, is relevant for Italy.

\footnotetext{
${ }^{3}$ It is well known that redemption yields are a valid measure of spot rates only if the yield curve is flat. otherwise they just represent some average of the relevant spot rates. In principle, this problem can be solved by fitting a discount function to the yields at different maturities. We tried both a Nelson-Siegel function and the extended Nelson-Siegel function proposed and discussed by Svensson (1994), but failed to achieve convergence for a non negligible number of points for the Italian data in our sample. Such result can be explained by considering the difference in traded volumes for the fixed interest swaps on Italian lire, where the three-years and the ten-years are highly traded while the market for five-yeas is rather thin.
} 


\section{Taxation}

If the interest income is only subject to personal income taxation, non-residents receive a gross payment. If it is subject to a withholding tax, residents and non-residents alike receive a net payment, with the possibility of reimbursement of the withholding tax to non-resident holders, or of reimbursement conditional on the existence of a taxation treaty: in the extreme case in which in one of the two countries there is a withholding tax which is not reimbursable to non residents, the whole amount of the latter will be reflected in the differential.

Amongst the high yielders, Italy subjects interest payments to a withholding tax of $12.5 \%$ with subsequent reimbursement to non-residents established in countries with which Italy has a specific tax treaty to that effect: to British or French residents, for instance, but not to US, Japanese and Swiss residents. In the case of Spain, instead, all non-residents are exempt from local taxes and receive a gross interest payment directly. Reimbursement of the Italian tax to non-residents used to take a long time; after 1993 procedural simplifications have reduced the lag to 30-60 days. The Italian tax treatment must thus account for a fraction of the overall spread. If we confine our treatment to (11), we implicitly include the tax effect in the default risk, with an overestimation of the latter.

In fact, taking a 10-year bond issued at par, our annually compounded gross redemption yield, $i$, is determined as follows:

$$
P=\frac{C}{l+R}+\frac{C}{(1+R)^{2}}+\ldots+\frac{C+100}{(1+R)^{10}}
$$

Where $\mathrm{P}$ is the quoted price, $\mathrm{C}$ is the coupon. The net redemption yield should be computed as follows:

$$
P=\frac{C(1-\tau)}{1+\text { in }}+\frac{C(1-\tau)}{(1+\text { in })^{2}}+\ldots+\frac{(1-\tau) C+100}{(1+\text { in })^{10}}
$$

where in is the net redemption yield, and $\tau$ is the withholding tax. While (12) would overestimate the default risk, as it assumes that there is no tax effect on the yield differential, (13) would certainly deliver an underestimation of it, because it is based on the assumption that the withholding tax is never reimbursed. The correct measure of yield would probably be given by the following formula:

$$
P=\frac{C\left(1-\beta_{t} \tau\right)}{1+i c}+\frac{C\left(1-\beta_{t} \tau\right)}{(1+i c)^{2}}+\ldots+\frac{\left(1-\beta_{t} \tau\right) C+100}{(1+i c)^{10}}
$$

where ic is the corrected yield and $\beta_{t}$ is a time-varying parameter which captures the confidence of the market on the procedure of reimbursement of the withholding tax and takes values in the range between zero ( no confidence in the recovery of the withholding tax) and one (full confidence in the immediate recovery of the withholding tax).

It is not easy to arrive at an independent measure of $\beta_{t}$. First such factor will increase or decrease with the speed of reimbursement to those who are entitled to it. Second, its overall effect on the spread depends on the share of market participants who are entitled to reimbursement relative to that of those who are not, and this share varies with market conditions. The importance of the second factor is likely to be limited because most Italian government bonds traded abroad are traded in London by market makers who are entitled to reimbursement. We thus neglect it. As for the first factor, we have a measure of $\beta_{\mathrm{t}}$. Since 1992, several banks -- Morgan Stanley Int. for example -- have been 
issuing factoring-type contracts that guarantee the repayment of the withholding tax at a price determined as a fixed percentage of the total withholding tax. Such percentage is reported in Figure 6. The price of the guarantee decreases over time, reflecting both the increased efficiency in the reimbursement procedures and, possibly, the increased competition in the supply of such derivatives. Assuming that the first effect dominates, we can then define the price as $\left(1-\beta_{t}\right)$. To give an idea of the correction take the case of a perpetuity floating at the par, we then have :

$$
\mathrm{i}-\mathrm{ic}=\mathrm{C} \beta_{\mathrm{t}} \tau
$$

Knowing the price and the coupon payment, (i-ic) can be also computed for the relevant cases. If we take a 10-year bond the percentage loss due to the not guaranteed part of the withholding tax can be readily computed and so $i$ and $i c$ can be derived (see figure 6). Given $i$ and $i c$ we can finally compute their continuously compounded equivalents and derive gross and corrected measures of the default risk premium. Such measures are reported in the bottom panel of figure 6 , where we can observe directly the impact of the withholding tax effect over the sample.

\section{Interest rates spreads, the exchange rate regime, and the maturity profile}

In this section we shall consider the first three of the issues listed above, deferring the discussion of the determinants of the yield differentials and of the interaction between exchange risk and default risk to the following section.

\section{A single common trend for total yield differentials and exchange rate factors?}

First, are the movements of the three countries' total yield differentials driven by a single common trend? Inspection of figures 4 and 5 suggests that the answer is negative -- although the three series show some comovements during specific episodes, such as the EMS crisis in 1992, and the rally of the DM in the Spring of 1995. A formal check can be implemented by using the Johansen [1994] procedure on a VAR in levels for the three variables. The results of such a test, using daily data over the sample January 1993 to September 1995, are shown in Table 1.

We consider total yield differentials computed on continuously compounded data (gross for Spain and Sweden, SPESPIOC and SPSWE10C, respectively, and corrected for the effect of the withholding tax in the case of Italy, SPTAX), and then exchange rate factors, computed as the differential between interest rate swaps denominated in high yielders' currencies and swaps denominated in D-marks (ERESP10C, ERSWE 10C and ERITA 10C, respectively).

First the test reveals that both total yield differentials and exchange rate factors are nonstationary. If interest rates differentials reflect expectations of exchange rate depreciation, and the exchange risk premium is stationary, this finding implies that the level of the exchange rate behaves in our sample as a variable integrated of order two, and that the expected rate of depreciation is not mean reverting. Note that in any "forward looking "model of the exchange rate the expected rate of depreciation can only be non-stationary if the difference between the "fundamentals" is non stationary. This finding suggests that markets expect the difference between fundamentals in high-yielders and in Germany to be non-stationary. 
Second, both for total yield differentials and for exchange rate factors, we cannot reject the hypothesis of the existence of at most one cointegrating vector. Hence, we can reject the hypothesis of the existence of a single common trend, which would imply two cointegrating vectors between the three series. Figure 4 confirms the statistical result, and suggests that there is indeed a common trend between the spreads on Italian and Spanish government bonds, which is not however shared by the spread on the Swedish government bonds. Formal testing of such hypothesis gives strong evidence in favour of the exclusion of Sweden when exchange rate factors are considered and weaker evidence in favour of the same exclusion when total yield differentials are considered.

\section{Exchange rate factors and the ERM}

Next, does membership of the ERM make a difference in the behaviour of the exchange rate component of the differential? Remember that: Sweden has never been a member of the ERM, although a policy of unilateral exchange rate pegging to the D-mark was pursued until September 1992, when it was discontinued; Italy abandoned the ERM on September 17, 1992; Spain has remained a member, though the peseta devalued twice in 1992, once in 1993 and once in 1995 and has made use since August 1993 of the enlarged fluctuation band.

The exchange rate factors for the three countries, as defined in equation (12), are reported in figures 4.2 and 5.2 for the maturities of 10 and 3 years respectively. Figures 7.1 and 7.2 show the difference between the Italian exchange rate factor, on the one hand, and the Spanish and Swedish factorsa, on the other, for the two maturities considered; the average of this difference is reported in the table below for the entire sample period and for a shorter period which excludes the currency crisis of September 1992 and the turbulence that persisted for the rest of the year. First, we note a very close association between the Italian and Spanish exchange rate factors, also confirmed by the cointegration analysis reported in Table 1 , while the Swedish exchange rate factor shows a somewhat different behaviour, especially in the first two years of the sample. Second, the Swedish exchange rate factor is the lowest of the three in the entire sample period and for both maturities, with the exception of few short interludes, while the difference between the Italian and the Spanish premia seems to revert to a zero mean, especially after 1992. Peaks and troughs in the latter difference are often connected to specific episodes affecting the individual currency.

\section{Exchange Rate Factors: average differentials}

(basis points, standard deviation in brackets)

\begin{tabular}{|c|c|c|}
\hline & January 1992-Sept 1995 & January 1993-Sept 1995 \\
\hline ITALY-SPAIN 3 Years & $\begin{array}{c}4 \\
(52.9)\end{array}$ & $\begin{array}{c}0.9 \\
(50.3)\end{array}$ \\
\hline $\begin{array}{lll}\text { ITALY-SPAIN } & 10 \text { Years }\end{array}$ & $\begin{array}{c}24.4 \\
(42.3)\end{array}$ & $\begin{array}{c}2.5 \\
(32.5)\end{array}$ \\
\hline ITALY-SWEDEN 3 Years & $\begin{array}{l}115.5 \\
(73.4) \\
\end{array}$ & $\begin{array}{l}110.33 \\
(71.3)\end{array}$ \\
\hline ITALY-SWEDEN 10 Years & $\begin{array}{c}93.2 \\
(74.5) \\
\end{array}$ & $\begin{array}{c}70 \\
(70.5)\end{array}$ \\
\hline
\end{tabular}

Thus, for weak currencies, belonging to the ERM -- or at least to the latest version of it -- does not seem to have any relevant effect on the exchange rate component of the yield differential. This is perhaps natural, considering the width of the new fluctuation band (the upper intervention limit exceeds by almost $35 \%$ the lower limit). It is however remarkable that even this tolerance is not sufficient, in the 
case of the peseta, to deliver interest rates consistent with the central ERM parity. In figure 8.1 and 8.2 we compare the swap rate for pesetas for the 3 and 10 years maturity with the maximum interest rate compatible with the central peseta-D-mark parity prevailing in each period, computed according to Svensson (1991) ${ }^{4}$. For the ten-year maturity the swap rate by far exceeds the maximum rate for the entire sample period. This is also true for the three years maturity, except for short periods.

\section{The maturity structure of yield differentials}

We next consider the maturity structure of the yield differentials, which depends on the maturity structure of their two components.

Consider first ER, the exchange-rate component of the total spread, for two maturities, $\mathrm{T}$ and $T^{\prime}<T$. From equations (2) and (10) we have:

$$
\left(I S_{j, t, T}-I S_{g, t, T}\right)-\left(I S_{j, t, T^{\prime}}-I S_{g, t, T}\right)=\left[\frac{1}{T}\left(\ln E_{t} S_{t+T}-\ln S_{t}\right)\right]-\left[\frac{1}{T}\left(\ln E_{t} S_{t+T^{\prime}}-\ln S_{t}\right)\right]
$$

where the member on the r.h.s. is the difference between the yearly average rates of the continuously compounded depreciation expected between $t$ and $T$ and between $t$ and $T$ '. Thus, the difference between the spreads for the two maturities on the I.h.s. will be positive, zero or negative, according to whether the average rate of depreciation between $T$ ' and $T$ is projected to be higher than, equal to or lower than that expected between $t$ and $T$ '. The maturity structure of the spreads will thus depend on the maturity structure of exchange rate expectations. What can we conjecture about the latter?

If the j-country's currency is floating, it is plausible that the bulk of depreciation is projected to occur in the nearer future: it is plausible therefore that the first term declines with $T$, the maturity of the bond. Not necessarily so if the currency is pegged to another currency in some exchange rate agreement. Expectations here may discount either a one-shot devaluation in the currency's parity, or the abandonment of the agreement, with the passage from pegging to free floating, followed by a cumulative devaluation of the currency: the time profile of expected depreciation will vary accordingly.

Figure 9 reports the differences between the 10 and the 3 years and the 10 and the 5 years exchange rate factors for Italy, Spain and Sweden. We can divide the sample period into three subperiods: one until the first symptoms of the exchange rate crisis of 1992; one encompassing the crisis and the following period of turbulence which lasted until the late summer of 1993; and the rest of the period, when the peseta, though remaining within the exchange rate mechanism of the EMS, was allowed to float within the enlarged 15\% fluctuation band established on August 1st 1993. Our conjecture, that under floating rates the expected rate of depreciation is higher in the nearer future and then declines for more distant horizons, is fully confirmed for the last period: in the three countries, and for the three maturities considered, the exchange rate factor declines consistently over time. This seems to have become a permanent feature of the weaker currencies: Sweden is no exception in this context, and we note again that there is no difference between an ERM currency, like the peseta, and the other two. An implication of this regularity is that, as the German yield curve has had a positive inclination since the fall of 1992 (see figure 10), the weaker currencies' swap yield curve is flatter than the German one (and may even have a negative slope).

\footnotetext{
${ }^{4}$ From (2). (3) and (12) in the text, $I_{s, L T} \max =I_{g, h T}+1 / T[\ln S m a x-\ln S(t)]$, where IS(s) is the peseta swap rate, IS $(g)$ is the Dmark swap rate, Smax is the peseta-DMark upper intervention limit. If IS(s)>IS(s)max, the expected exchange rate ES exceeds the maximum depreciation allowed by the given central parity.
} 
. The period including the September crisis and the turbulence that followed (the peseta devalued its central parity twice in 1993 before the enlargement of the band) is characterised by a high variability of the maturity structure of the premia in the three countries, with a prevailing negative slope for Italy and Spain, but not for Sweden.

One common observation for the whole sample period is that the slope of the weaker currencies' swap yield curve is always smaller and more stable than that of the German curve: as long as the latter was negative, that for the lira and the peseta was flatter or with a positive slope; as the inclination of the German curve changed, that of the weaker currencies changed by much less.

There is no obvious prior regarding the term structure of default risk premia. Figure 11 reports the term structure of the default risk premia on Italian and Spanish government bonds (we do not report the Swedish data, as the default premium is insignificant and at times negative in the case of Sweden) ${ }^{5}$. In the case of Italy, since the fall of 1993 the difference between the default premia of the 10 and the 3 year bonds, though highly variable, is consistently positive, with peaks coinciding with episodes of political crises, as those occurring between the summer of 1994 and the spring of 1995 . This could be taken as evidence that the default premium increases with the maturity, especially under unfavourable shocks. The behaviour of the difference between the 10 and the 5 year default premia seems however to point in the opposite direction: it is consistently negative, though narrowing in response to political shocks. An explanation provided by market participants is that there is little international demand for the 5 year maturity, as investors prefer shorter durations, while arbitrage and derivative trading concentrates on the 10 year bonds: 5 year bonds thus trade mostly in the domestic segment of the market and, as a result, they do not offer reliable indications on the yield structure. The case of Spain is similar to that of Italy, though, unlike in the Italian case, the default premium oscillates around zero: when the premium becomes positive, as a result of a domestic shock, so does its difference between the 10 and the 3 year maturities, while the difference between the 10 and the 5 year premium reacts in the same way to shocks, but is on average zero or negative.

Finally, the behaviour of the maturity structure of the total yield differentials between the Italian and Spanish and the German government bonds is reported in figure 12. In the case of the difference between the 10 and the 3 year spreads, the exchange and the default premia work, as we have seen, in an opposite direction. For lira bonds, barring very sizeable shocks to the default premium, the former effect prevails; for peseta bonds, the offset between the two effects is more frequent. In the case of the difference between the 10 and the 5 year maturities, instead, the two effects tend to work in the same direction. On the whole our earlier conclusion of a flatter swap yield curve for weaker currencies with respect to Germany can be extended to the yields of Government bonds, though there may be irregularities in the 5 year segment.

\footnotetext{
${ }^{5}$ In the case of Italy, the data are not corrected for the effects of taxation, as the proxy we use for correcting the 10 year yields is not available for the 3 and 5 year bonds: unless we assume that the effect is the same for all maturities, the behaviour of the differences between the 10 year default risk premia and those on the other two maturities may be biased in the first part of the sample, when the correction is sizeable
} 


\section{International and country-specific determinants of the total spread}

\section{The econometric strategy}

In this section we study how total spreads are affected by international and country specific shocks. Our econometric analysis uses daily observations for the period January 1993-October 1995 (to avoid the turbulence of 1992) and it is based on two Vector Autoregressive Models, one for Italy and one for Spain, each including two variables: the total spread, SP and one of its components, ER. We exclude Sweden on the basis of our finding in section 3 that there is a single common trend between the Italian and Spanish spreads, not shared by Swedish spreads.

In our investigation we separate the analysis of the long-run equilibrium relationships from the analysis of the dynamic adjustment in response to shocks. We base our equilibrium analysis on the application of the Maximum Likelihood Procedure developed by Johansen $(1988,1992,1994)$ to investigate the cointegration properties of a non-stationary dynamic system. Having established the cointegration properties of the system we study its short-run response to shocks by implementing Impulse Response Analysis.

The base-line of our empirical investigation is the specification of a probabilistic structure for our data, given by a Vector Autoregressive Model [see, for example, Pagan, 1994]. Abstracting from the treatment of the deterministic part, we start by specifying the following base-line autoregressive model for the variables SP and ER.

$$
\begin{aligned}
& \left(\begin{array}{c}
E R_{t} \\
S P_{t}
\end{array}\right)=A_{1}\left(\begin{array}{c}
E R_{t-1} \\
S P_{t-1}
\end{array}\right)+\left(\begin{array}{c}
v_{1 t} \\
v_{2 t}
\end{array}\right) \\
& \left(\begin{array}{c}
v_{1 t} \\
v_{2 t}
\end{array}\right) \sim N(0, \Omega)
\end{aligned}
$$

(17) is specified with a lag length of one, which turns out to be empirically supported in our case by the traditional lag truncation criteria.

Because we estimate the VAR on non-stationary time series the unconditional distribution of our statistical model is not defined. This means that inference based on standard distribution cannot be applied and the autoregressive representation cannot be inverted to obtain the moving average representation necessary for the analysis of the short-run dynamics. To properly deal with this issue we use system cointegration analysis as proposed by Johansen $(1988,1992,1994)$ and represent the VAR in (15) as follows:

$$
\begin{aligned}
& \left(\begin{array}{c}
\Delta E R_{t} \\
\Delta S P_{t}
\end{array}\right)=(A(1))\left(\begin{array}{c}
E R_{t-1} \\
S P_{t-1}
\end{array}\right)+\left(\begin{array}{c}
v_{1 t} \\
v_{2 t}
\end{array}\right) \\
& A(1)=-\left(I-A_{1}\right)
\end{aligned}
$$

Note that (18) is a re-parameterization of (17) and that the two systems have the same residuals. The matrix $A(1)$ captures the long-run solution of this simple dynamic system. In (18) we have three cases of interest:

(i) A(1) has full rank, in which case the system is stationary; 
(ii) $A(1)$ has zero rank, in which case the system is non-stationary and no linear combination of the variables included in it is stationary;

(iii) $A(1)$ has reduced rank $k=1$, in which case the system is non-stationary but there is one cointegrating relationship, i.e. a linear combination of the variables included in the system is stationary

In this case we have: $A(1)=\alpha \beta$ where $\alpha$ is a (2x 1) matrix of loadings and $B$ is a matrix $(2 \times 1)$ of coefficients in the cointegrating vectors.

Note that in case (i) traditional inference and inversion of the vector autoregressive representation can be carried out on the VAR in levels. In case (ii) the common procedure of specifying the VAR in first differences would correctly allow inversion and application of standard inference without loss of relevant information. In case (iii) correct treatment of cointegration and the derivation of the long-run solution is necessary in order to have a fully informative probabilistic structure. ${ }^{6}$

The results of testing for cointegration in the Spanish and the Italian case are reported in Tables 2 and 3. The analysis reveals non-stationarity for both systems. The hypothesis of no cointegration between ER and SP is rejected for both countries, with stronger evidence for the Spanish case, while the hypothesis of the existence of at most one cointegrating vector can never be rejected. On the basis of this evidence we represent the system as follows:

$$
\left(\begin{array}{c}
\Delta E R_{t} \\
\Delta S P_{t}
\end{array}\right)=\left(\begin{array}{l}
\alpha_{1} \\
\alpha_{2}
\end{array}\right)\left(\begin{array}{ll}
1 & \beta
\end{array}\right)\left(\begin{array}{c}
E R_{t-1} \\
S P_{t-1}
\end{array}\right)+\left(\begin{array}{l}
v_{1 t} \\
v_{2 t}
\end{array}\right)
$$

Where representation (19) has been obtained by normalising the cointegrating vector with respect to SP.

Having found cointegration we next test the hypothesis that the cointegrating vector has the form $[1,-1]$, i.e. that the default risk premium is stationary. In (19) we thus test the null $\beta=-1$. Such restriction cannot be rejected in either cases, with stronger evidence for Spain.

Having solved the identification of the long-run equilibrium of the model we are left with the following stationary representation of the original VAR:

$$
\begin{aligned}
& \Delta E R_{t}=\alpha_{1}\left(S P_{t-1}-E R_{t-1}\right)+v_{1 t} \\
& \Delta S P_{t}=\alpha_{2}\left(S P_{t-1}-E R_{t-1}\right)+v_{2 t}
\end{aligned}
$$

This representation is known as the Vector Error Correction Representation. This is a stationary autoregressive representation: it involves first differences of non-stationary variables and the stationary cointegrating vector (the default premium, $D R=S P-E R$ ). The existence of a long-run cointegrating relationship provides evidence for a causal link between the exchange rate factor and the total spread, without being informative on the direction of such link. However, the direction of causality can be established by analysing the adjustment coefficients $\alpha$. Intuitively, a negative and significant $\alpha_{2}$

\footnotetext{
${ }^{6}$ In general, when there is a multiplicity of cointegrating vectors, the imposition of identifying restricitions on the long-run solutions is necessary to achieve identification [see Giannini(1992) e Johansen(1994)]. As we concentrate on a bivariate system there is no identification problem for the cointegrating vector, which, if existing, is unique.
} 
paired with a non significant $\alpha_{1}$ provides evidence that, in presence of deviations from the long-run equilibrium, the total yield differential adjusts to restore equilibrium while the exchange rate factor does not. We can then infer that the causality runs unidirectionally from the exchange rate factor to the total differential. The converse would hold if the evidence on the $\alpha$ 's was reversed, while we have contemporaneous feedback if both adjustment coefficients are significant.

The causality analysis based on the adjustment coefficient in the cointegrated VAR suggest that for both countries there is univariate causality from the exchange rate factor to the total differential. In other words the exchange rate factor behaves like a pure random walk and the evidence of stationarity of the default risk is to be interpreted as a result of a causal link running from ER to SP.

Having established that the long-run equilibrium properties of the Italian and the Spanish case are similar, we move to the analysis of the short-run dynamics of the system. Impulse response and variance decomposition analysis describe the dynamic response of the system to shocks of interest. This requires the identification of structural shocks and the derivation of the moving average representation of the VAR. The Error Correction Representation (20) is not suitable to these exercises for two reasons: (a) the derivation of the moving average representation of (20) is not immediate; (b) the residuals of (20) are reduced form residuals: as such they cannot be interpreted as shocks to some structural relations and, being correlated, they do not allow the analysis of the response of the system to a particular shock independently from other shocks.

In order to solve both these problems we think of $(20)$ as a reduced form representation of the following structural model:

$$
\begin{aligned}
\Delta E R_{t} & =\alpha_{1}\left(S_{t-1}-E R_{t-1}\right)+b_{11} u_{1 t}+b_{12} u_{2 t} \\
\Delta S P_{t} & =\alpha_{2}\left(S_{t-1}-E R_{t-1}\right)+b_{21} u_{1 t}+b_{22} u_{2 t} \\
\left(\begin{array}{l}
u_{1 t} \\
u_{2 t}
\end{array}\right) & \sim \text { N.I.D. }(0, I)
\end{aligned}
$$

Note that the structural residuals are assumed to be orthogonal to each other,

Within our structural model (21) we deal with problems (a) and (b) mentioned above. In order to derive the moving average representation of the system we re-write (21) in the following equivalent form:

$$
\begin{aligned}
& \left(\begin{array}{cc}
-1 & 1 \\
0 & 1
\end{array}\right)\left(\begin{array}{cc}
1-L & 0 \\
0 & 1
\end{array}\right)\left[\begin{array}{l}
D R_{t} \\
\Delta S_{t}
\end{array}\right]=\left(\begin{array}{cc}
\alpha_{1} & 0 \\
\alpha_{2} & 0
\end{array}\right)\left[\begin{array}{l}
D R_{t-1} \\
\Delta P_{t-1}
\end{array}\right]+\left(\begin{array}{ll}
b_{11} & b_{12} \\
b_{21} & b_{22}
\end{array}\right)\left[\begin{array}{l}
u_{1 t} \\
u_{2 t}
\end{array}\right] \\
& \left(\begin{array}{l}
u_{1 t} \\
u_{2 t}
\end{array}\right) \sim \text { N.I.D. }(0, I)
\end{aligned}
$$

where $L$ is the lag operator. Note that (22) and (21) have the same residuals; however (22) exploits the cointegration result to derive a stationary VAR representation. Both variables modelled in (22) are stationary: DR is the cointegrating relation and $\Delta S P$ is the first difference of a I(1) variable.

We are now left with the problem of identifying the structural shocks of interest. Our cointegrating evidence suggests that the total yield differential is cointegrated with and caused by the exchange rate factor. Moreover, Italian and Spanish exchange rate factors are cointegrated. The 
evidence from the long-run seems to suggest the identification of two type of shocks: a permanent shock and a transitory shock. We interpret the permanent shock as the structural shock to exchange rate factors and identify it from the transitory shock by imposing that the transitory shock has no permanent effect on the total yield differential.

The evidence of cointegration between the Italian and Spanish exchange rate factors gives an international flavour to the permanent shocks, in that they are shared by the two countries, while the transitory shock should capture local elements. Based on this observation we label the permanent shock, $u_{11}$, as "international" and the transitory shock, $u_{2 t}$, as "local". We estimate two independent VARs, one for each country. The estimation of two separate VARs allows an additional check of our choice to interpret permanent shocks as international and transitory shocks as local, since we can analyse the correlations between shocks independently generated. Clearly we do so at the cost of some loss in efficiency. Additional evidence indicating that permanent shocks are associated with international rather than country-specific factors comes from regression of these shocks on innovations in international variables, such as the US dollar-D mark exchange rate and the long term German interest rate. On the contrary, local shocks are not significantly affected by innovations in international variables.(these regressions are reported in the next section) The identification of shocks achieved by separating a permanent shock from a transitory shock has been originally proposed by Blanchard-Quah (1989) and it has been rather widely used in different contexts after their original contribution [see Pagan(1994)].

In practice, the solution to the identification problem consists of the unequivocal derivation of estimates of the parameters $b_{i j}$ and of the structural shocks in (19) given the knowledge of the innovation in the VAR reduced form (20). Such problem can be effectively illustrated by considering the General Method of Moments (GMM) estimation approach. ${ }^{7}$ Taking on account the restriction linking the reduced from representation and the structural form representation of our VAR, we can write:

$$
\mathbf{u}_{\mathrm{t}} \mathbf{u}_{\mathrm{t}}{ }^{\prime}=\mathbf{B}^{-1} \mathbf{v}_{\mathrm{t}} \mathbf{v}_{\mathrm{t}}{ }^{\prime} \mathbf{B}^{-1}
$$

Defining as $M$ the sample variance-covariance matrix of the VAR innovations, taking the expected value of (21) and equating sample moment to population moments, we have:

$$
\hat{\Omega}=\hat{\mathbf{B}}^{-1} \hat{\mathbf{M B}}^{-1}
$$

We achieve identification if we can derive uniquely the parameters in $\Omega$ and $B$, given the observation of $\mathrm{M}$. A necessary condition for identification is that the number of equation in (24) equals the number of unknowns. In our case we have two variables included in the VAR and the matrix M contains three elements. Therefore at most three parameters can be identified. By imposing one restriction on the elements of the $B$ matrix we have a just-identified system; by imposing more than one restriction on the elements of the B matrix we have an over-identified system and tests for the validity of over-identifying restrictions can be implemented[see, for example, Giannini(1992)].

To show how we achieve identification, derive the long-run response of DR and $\triangle S P$ to the structural shocks of interest. From (22) we have

\footnotetext{
' Our estimation is based on a Full Information Maximum Likelihood Method implemented within the RATS procedure MALCOLM writtten by Rocco Mosconi and kindly made available to us. MALCOLM now incorporates the procedure for the derivation of impulse response functions and variance decomposition written by Giannini, Lanzarotti and Seghelini and discussed in Giannini(1992).
} 


$$
\left(\left(\begin{array}{cc}
-1 & 1 \\
0 & 1
\end{array}\right)\left(\begin{array}{cc}
1-L & 0 \\
0 & 1
\end{array}\right)+\left(\begin{array}{cc}
-\alpha_{1} L & 0 \\
-\alpha_{2} L & 0
\end{array}\right)\right)\left[\begin{array}{l}
D R_{t} \\
\Delta S P_{t}
\end{array}\right]=\left(\begin{array}{ll}
b_{11} & b_{12} \\
b_{21} & b_{22}
\end{array}\right)\left[\begin{array}{l}
u_{1 t} \\
u_{2 t}
\end{array}\right]
$$

By setting $\mathrm{L}=1$ and by inverting the matrix premultiplying $\mathrm{DR}$ and $\Delta \mathrm{SP}$ we derive the long-run impact of shocks on variables of interests:

$$
\left[\begin{array}{l}
\mathrm{DR}_{\mathrm{t}} \\
\Delta \mathrm{SP}_{\mathrm{t}}
\end{array}\right]=\left(\begin{array}{ll}
-\alpha_{1} & 1 \\
-\alpha_{2} & 1
\end{array}\right)^{-1}\left(\begin{array}{ll}
\mathrm{b}_{11} & \mathrm{~b}_{12} \\
\mathrm{~b}_{21} & \mathrm{~b}_{22}
\end{array}\right)\left[\begin{array}{l}
\mathrm{u}_{1 \mathrm{t}} \\
\mathrm{u}_{2 \mathrm{t}}
\end{array}\right]=\frac{1}{\alpha_{2}-\alpha_{1}}\left(\begin{array}{cc}
1 & -1 \\
\alpha_{2} & -\alpha_{1}
\end{array}\right)\left(\begin{array}{ll}
\mathrm{b}_{11} & \mathrm{~b}_{12} \\
b_{21} & b_{22}
\end{array}\right)\left[\begin{array}{l}
u_{1 \mathrm{t}} \\
u_{2 t}
\end{array}\right]
$$

$$
\left[\begin{array}{c}
D R_{t} \\
\Delta S P_{t}
\end{array}\right]=\frac{1}{\alpha_{2}-\alpha_{1}}\left(\begin{array}{cc}
b_{11}-b_{21} & b_{12}-b_{22} \\
\alpha_{2} b_{11}-\alpha_{1} b_{21} & \alpha_{2} b_{12}-\alpha_{1} b_{11}
\end{array}\right)\left[\begin{array}{l}
u_{1 t} \\
u_{2 t}
\end{array}\right]
$$

$\mathrm{u}_{2 t}$ is the local shock, therefore we identify it by imposing that such shock does not have any long-run impact on the total yield differential. We impose the following restriction: $\alpha_{2} b_{12}-\alpha_{1} b_{11}=0$. In general, given that the parameters $\alpha_{1}$ and $\alpha_{2}$ have al ready been identified in the long-run analysis, this is the restriction that we need to just-identify the structural shocks of interest. However, from our longrun analysis we already know that $\alpha_{1}$ can be restricted to zero. Hence, in our case, the identification of permanent and transitory shocks is achieved by imposing the restriction: $b_{12}=0$.

Note that in this setting the Blanchard-Quah identification produces exactly the same results of a Choleski decomposition. Such equivalence has already been pointed out in a different context [Cochrane(1994)]. The intuition for this result goes as follows: if ER is a random walk and if a shock does not affect ER contemporaneously, then that shock does not affect ER in the long-run. Since ER and SP are cointegrated with a cointegrating vector $(1,-1)$, then a shock that does not affect ER in the long-nun does not affect SP in the long-run as well. Henceforth, identifying local shocks by assuming that they do not affect ER contemporaneously is equivalent to identifying such shocks by assuming that they do not affect SP in the long-run. ${ }^{8}$

We report in Table 4 the estimates of the parameters of the B matrix for our two countries of interest. For both countries the parameter $b_{21}$ is highly significant and it is higher for Italy.

Table 4 provides also evidence on the correlation among shocks identified as local and international for Italy and Spain. The permanent and the transitory shocks within each country are assumed orthogonal to each other. However our identification strategy does not impose any restriction on correlations across countries, thus the evidence of a high correlation of permanent shocks identified from the VARs for Italy and Spain and of low correlation between transitory shocks and between transitory shock for one country and permanent shock for the other could be interpreted as evidence not conflicting with our identification. From the table we note that the correlation between permanent shocks is by far the highest at .44 , while all the other correlations are low.

\footnotetext{
${ }^{8}$ This point was made clear to us by seminar participants when an earlier version of the paper was presented at the University of Modena
} 


\section{Dollar, Bunds and European Spreads}

We have documented that shocks identified as permanent are correlated across countries -- evidence which suggests that such shocks may be associated with common international factors. In this section we investigate what such international factors may be, and to what extent they affect, via the exchange rate factors, the total spreads. We also try to provide evidence showing that the transitory shocks may be labelled as "local" by checking if the determinants of the intemational shocks are significant in explaining transitory shocks. Under our identifying assumptions international factors should not be significant in the determination of transitory local shocks. We focus on three variables that are obvious candidates for international shocks: the Dollar/D-mark exchange rate, the 3-month Euro-mark rate and the 10-year interest rate on Bunds.

We proceed by first constructing time series for the innovations of each of the three international variables. We do so by taking the innovation from a VAR for these three variables. We then run simple OLS regressions of shocks identified as local and international on innovations in each of the three international variables. The results are reported in Table 5. In the case of Italy the innovations in international factors are not significant in explaining shocks identified as local and are highly significant in explaining shocks identified as international. Negative innovations in the Dmark/US dollar exchange rate, i.e. a depreciation of the dollar, are associated with positive international shocks which cause a widening of the spread. An innovation in the long-term German interest rate has the same effect with a much stronger significance: in fact it explains ten per cent of the variance of the international shocks while the innovation in the D-mark/US dollar exchange rate explains only about two per cent of the variance. German short-term rates are not significant in explaining our international shocks as identified from the VAR for Italy. The results for Spain are very closely associated with those for Italy, although innovations in the German short term rate are significant in explaining shocks identified as local for Spain. However, the joint test for significance of all regressors confirms a remarkable difference in the significance of international factors in the explanation of shocks identified as local and international.

\section{The dynamic response of spreads to local and international shocks}

We now have a stationary system and we have identified the shocks of interest. We can then analyse the short-run dynamics of our system by implementing impulse response analysis and variance decompositions ${ }^{9}$. Impulse responses and variance decompositions for the Italian and the Spanish case are reported in figures 13 and 14 . The comparison of the impulse response functions for the Italian and the Spanish case provides an interesting explanation for the different behaviour of the default risk premia in the two countries.

Looking at the Italian case we note that international shocks have a strong and significant simultaneous effect on the total differential, which converges to the long-run equilibrium value of one within forty observations. A country specific shock has no effect on the exchange rate factor but a

\footnotetext{
${ }^{9}$ The validity of the dynamic simulation of a VAR has been subjected to criticisms connected to the problem of the non-uniqueness of Moving Average representations (see Hansen-Sargent(1991) and Lippi-Reichlin(1993). The very short lag of our VAR model led us to believe that we are dealing with a pure vector autoregressive model and problems related to non-fundamental representations of the Moving Average component should not be relevant.
} 
rather persistent effect on the total spread. The Forecasting Error Variance Decomposition of the exchange rate factor depends always almost exclusively on the international shock, while the countryspecific shock contribution to the FEVD of the total spread is very high immediately after the shock and it dies away rather slowly towards zero. Spain clearly differs from Italy in that the converges toward the long-run equilibrium of value of one after an international shock is very quickly achieved and country specific shock have a quickly vanishing effect on the total spread. Such results are confirmed by the FEVD which shows total dependence of the exchange rate factor on the international shock at any horizon and a contribution of the country-specific shock to the FEVD of the total spread that becomes very close to zero twenty periods after the shock. We can conclude that there is a difference between the Italian and Spanish case in the adjustment toward equilibrium. In both countries the total yield differential is driven by international shocks, however country specific shocks leave a longer memory in the Italian total spread than in the Spanish one. ${ }^{10}$

\section{Conclusions}

This paper is a first attempt at evaluating the determinants of the total interest rate differentials on government bonds between high yielders and Germany. We have identified and measured two components of such differentials: one due to expectations of exchange rate depreciation -- which we call the exchange rate factor -- another which reflects the market assessment of default risk. We have proposed and discussed a measure of the exchange rate factors and of the default risk premium based on interest rates swaps.

We find that the total spreads on Italian and Spanish government bonds have a common trend, which is not shared by the Swedish spread. We also find that there is a very close association between the Italian and the Spanish exchange rate factors, and that the difference between the two tends to revert to a zero mean. Thus, contrary to the conventional wisdom widely accepted in policy discussions, in the case of weaker currencies, membership of the ERM is not sufficient to stabilise expectations and does not therefore affect the exchange rate component of the spread.

We next consider the maturity structure of the two components of the spread for Spain and Italy. Our conjecture that after the ERM crisis of September 1992 the average expected rate of depreciation is higher in the near future and then declines for more distant horizons, is confirmed for the three currencies. As for the default risk premium, the conjecture that it should be higher for longer maturities is fully borne out in the case of the 10-3 year differential, while the 5 year segment presents irregularities probably due to the structure of market demand. The effects of the exchange rate factor and of the default premium on the maturity structure of the total spread tend to work in opposite directions. On the whole, the net result is that high-yielders, unless there are sizeable domestic shocks to their default premia, have a maturity structure of their government bonds flatter and more stable than that of Germany

We then proceed to study how the total spread is affected by structural shocks. In our investigation we separate the long-run equilibrium analysis from the analysis of the short-run dynamic adjustment. We have estimated two VARs: one for Italy and one for Spain. Our main findings are:

\footnotetext{
${ }^{10}$ To check the consistency of the econometric results derived at the ten-year maturity we have considered alternative maturities, namely three and five years. The results form the impulse response analysis and the variace decompositions obtained at the ten-year maturiry are confirmed. Results are available upon request
} 
In the long-run total differentials are determined by exchange rate factors. We find evidence of cointegration between total differentials and exchange rate factors and of uni-directional causality going from the exchange rate factor to the total yield differential. Such evidence holds for both Italy and Spain, although the speed of adjustment to the long run equilibrium is higher in the Spanish case. This is evidence that in the long-run the total spreads for these two countries are dominated by a common "international" component. This finding does not extend to the spread on Swedish bonds, which, even in the long-run, appear to be driven by different factors.

Our short-rum analysis depends crucially on the results obtained for the long-run

Our cointegrating evidence suggests that the total yield differential is cointegrated with and caused by the exchange rate factor. Moreover, Italian and Spanish exchange rate factors are cointegrated. The evidence from the long-run seems to suggest the identification of two type of shocks: an international shock and a local shock. We interpret the intemational shock as the structural shock to exchange rate factors and identify it from the local shock by imposing that the local shock has no permanent effect on the total yield differential. The international shocks, although identified separately for Italy and Spain, are affected in a very remarkable similar way by shocks to the dollar/mark exchange rate and to longterm German interest rates.

In the short-run the Italian and Spanish spreads behave differently in that country specific shocks leave a longer memory in the Italian total spread than in the Spanish one.

Overall our investigation provides strong evidence in favour of the existence of a common trend for the Italian and Spanish spreads on Bunds. Such trend is driven by international factors and is independent from country-specific shocks. Country-specific shocks are only relevant in explaining short term cycles around the common stochastic trend. 


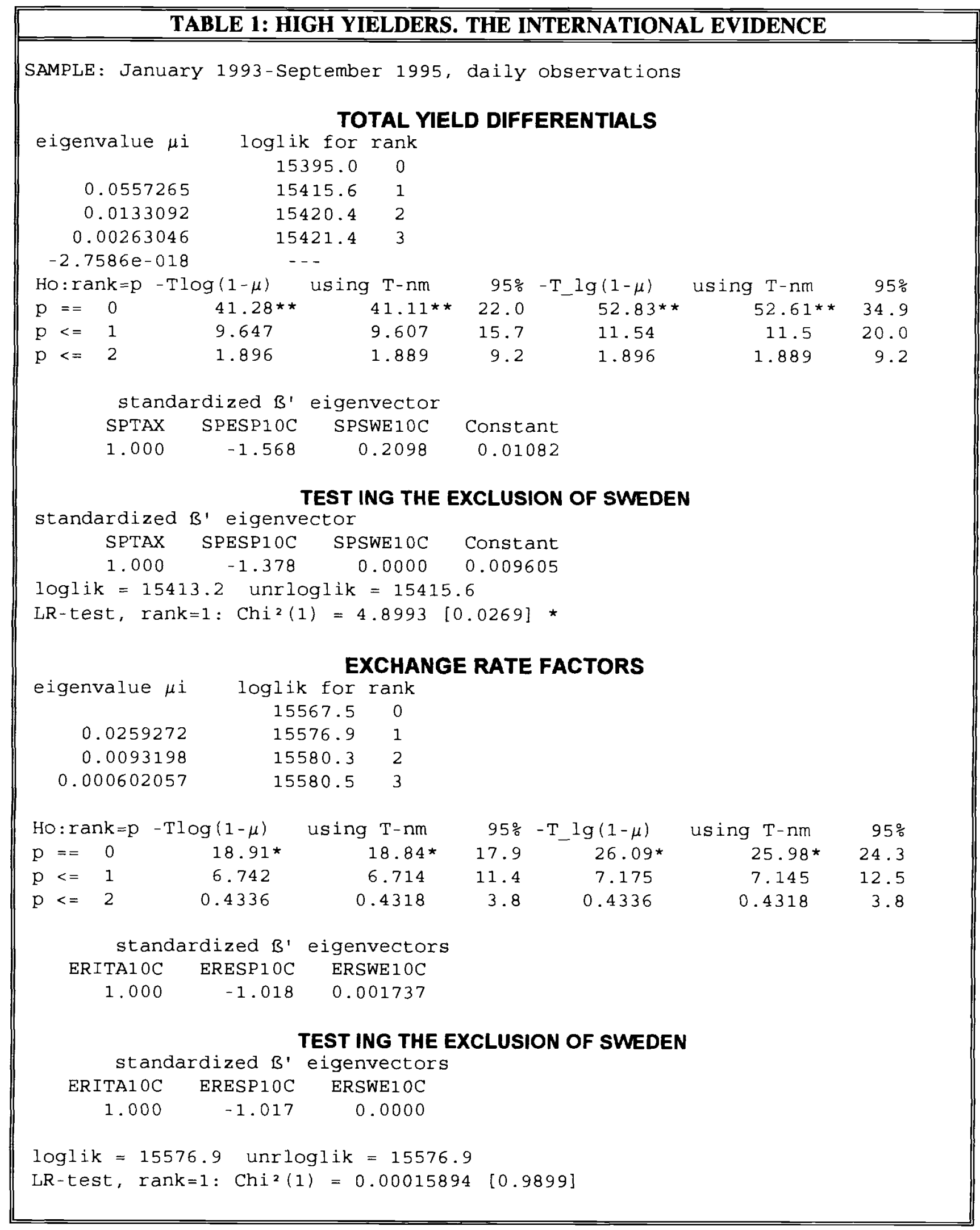




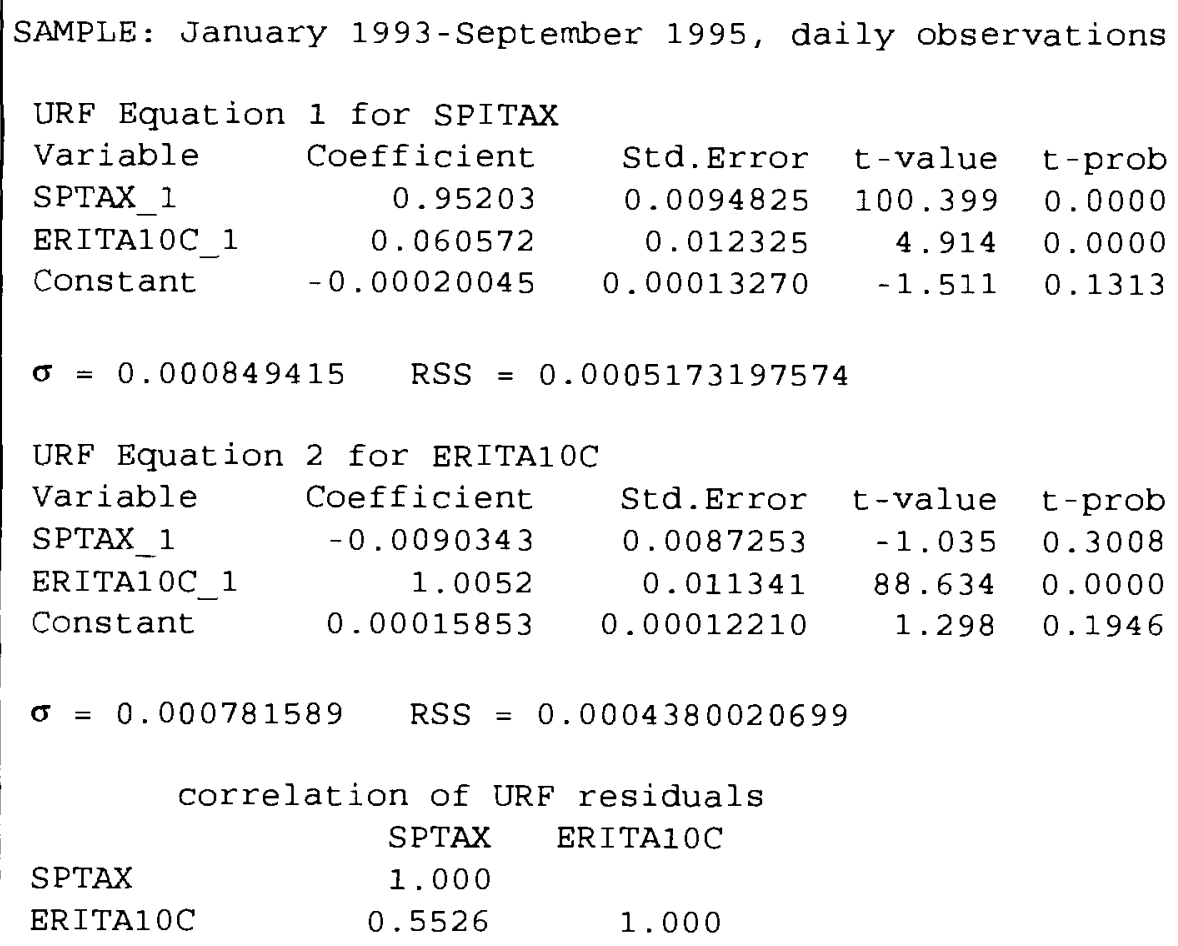




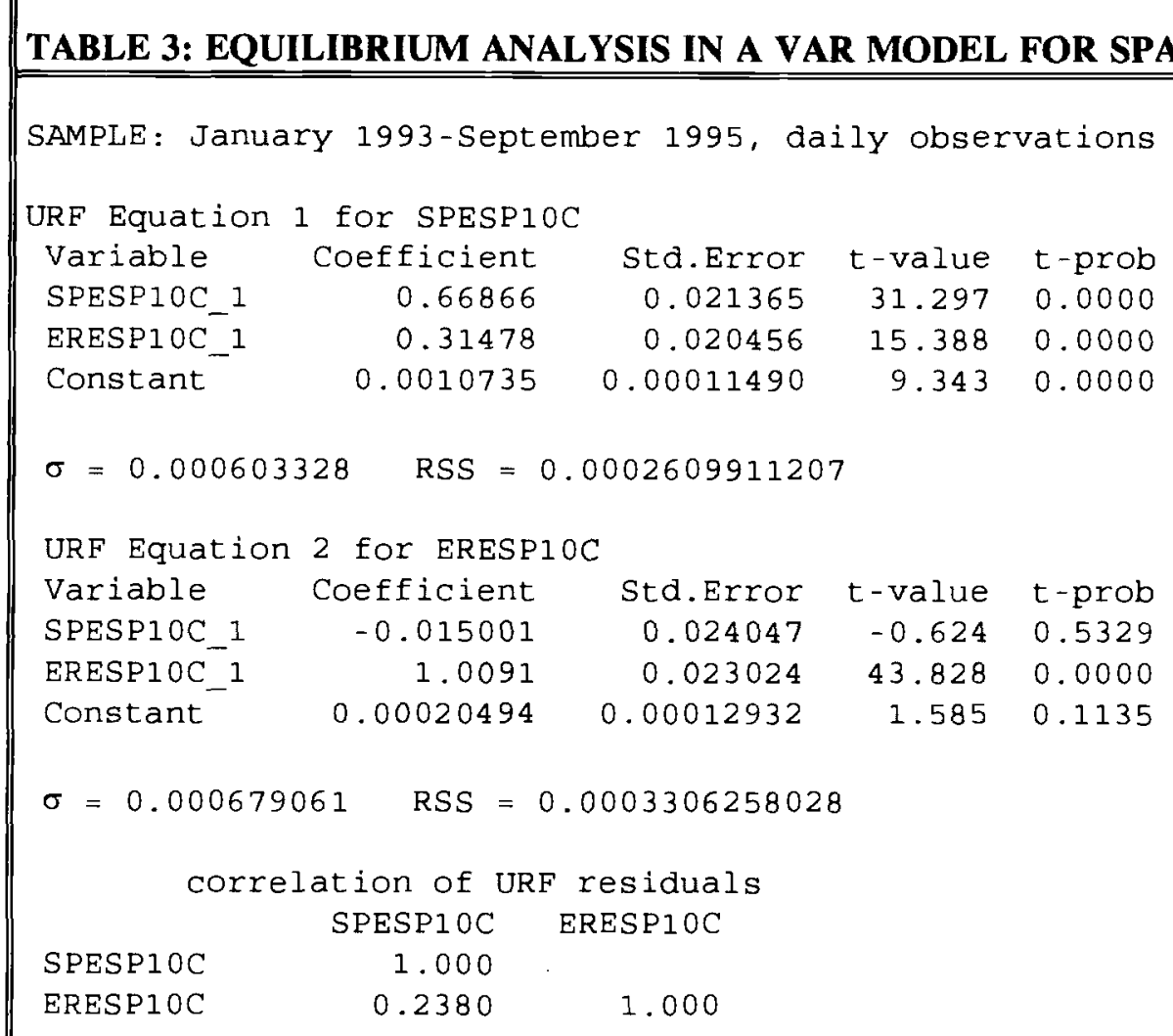

eigenvalue $\mu i \quad \log$ ik for rank

\section{Cointegration analysis}

$\begin{array}{rcc}0.259189 & 10504.0 & 0 \\ 0.00466198 & 10612.0 & 1 \\ 2.20226 e-018 & 10613.7 & 2\end{array}$

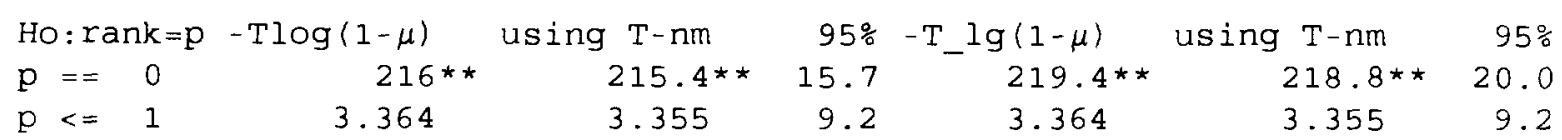

standardized $B$ ' eigenvectors

SPESPIOC ERESPIOC Constant

$\begin{array}{lll}1.000 & -0.9528 & -0.003155\end{array}$

standardized $\alpha$ coefficients

SPESP1OC $\quad-0.3312$

ERESPIOC $\quad-0.01417$

TESTING CAUSALITY

A matrix, imposing linear restricitions,

SPESPIOC $\quad-0.3282$

ERESP10C $\quad 0.0000$

$\log l i k=10611.8$ unrloglik $=10612$

LR-test, $\operatorname{rank}=1: \operatorname{Chi}^{2}(1)=0.34301 \quad[0.5581]$ 


\section{TABLE 4: STRUCTURALIZING THE VARS FOR ITALY AND SPAIN}

\section{ITALY}

\begin{tabular}{|c||c||c|c|}
\hline PARAMETER & COEFFICIENT & STD.ERROR & T-VALUE \\
\hline \hline $\mathrm{B}(2,1)$ & 0.595 & 0.0341 & 17.44 \\
\hline \hline $\mathrm{B}(1,1)$ & 0.00077 & 0.00002 & 37.92 \\
\hline $\mathrm{B}(2,2)$ & 0.00071 & 0.00002 & 37.92 \\
\hline PARAMETER & COEFFICIENT & STD.ERROR & T-VALUE \\
\hline \hline B(2,1) & 0.22 & 0.0327 & 6.38 \\
\hline $\mathrm{B}(1,1)$ & 0.00079 & 0.00002 & 38.00 \\
\hline $\mathrm{B}(2,2)$ & 0.00050 & 0.00001 & 38.00 \\
\hline \hline
\end{tabular}

The $\mathrm{B}(\mathrm{i}, \mathrm{j})$ parameters refers to te estimation of the following model:

$$
\begin{aligned}
& {\left[\begin{array}{l}
\Delta E R_{t} \\
\Delta S P_{t}
\end{array}\right]=\left(\begin{array}{cc}
0 & 0 \\
\alpha_{2} & 0
\end{array}\right)\left[\begin{array}{c}
D R_{t-1} \\
\Delta S P_{t-1}
\end{array}\right]+\left(\begin{array}{cc}
b_{11} & 0 \\
b_{21} & b_{22}
\end{array}\right)\left[\begin{array}{l}
u_{1 t} \\
u_{2 t}
\end{array}\right]} \\
& \left(\begin{array}{l}
u_{1 t} \\
u_{2 t}
\end{array}\right) \sim \text { N. I. D. }(0, I)
\end{aligned}
$$

N.B. $u_{11}$ is the permanent shock, $u_{21}$ is the transitory shock. The Italian Default risk is corrected for the withholding tax effect

\begin{tabular}{|c|c|c|c|c|}
\hline & TRANITA & TRANESP & PERITA & PERESP \\
\hline TRANITA & 1.000 & 0.15 & 0.000 & 0.07 \\
\hline TRANESP & 0.15 & 1.000 & -0.02 & 0.000 \\
\hline PERTITA & 0.000 & -0.02 & 1.000 & 0.44 \\
\hline PERESP & 0.07 & 0.000 & $\overline{0.44}$ & 1.000 \\
\hline
\end{tabular}

TABLE 4.1: CORRELATION MATRIX OF STRUCTURAL SHOCKS

TRANITA is the transitory shock identified in the VAR for Italy, PERITA is the permanent shock identified in the VAR for Italy. TRANESP is the transitory shock identified in the VAR for Spain, PERESP is the permanentl shock identified in the VAR for Spain.

All Statistical results are computed on the full sample of daily observations (Jan 93-Oct 95). Results in Table 4.1 are based on OLS regressions. 


\section{TABLE 5: THE DETERMINANTS OF STRUCTURAL SHOCKS}

OLS regressions of innovations to the shock identified as international and to the shock identified as local on innovations on the right hand-side variables. Standard errors in parenthesis; percentage of the total variance of the dependent variable explained by each regressor in brackets.

\begin{tabular}{|c|c|c|c|c|}
\hline $\begin{array}{c}\text { Dependent } \\
\text { Variable }\end{array}$ & $\begin{array}{c}\text { D-mark /US } \\
\text { dollar } \\
\text { exchange rate }\end{array}$ & $\begin{array}{l}\text { Ten-Year-Bund } \\
\text { Interest Rate }\end{array}$ & \begin{tabular}{|c|} 
Three-month \\
German euro-rate
\end{tabular} & \begin{tabular}{|c|} 
Joint Significance \\
of all regressors
\end{tabular} \\
\hline $\begin{array}{c}\text { Local Shock } \\
\text { ITALY }\end{array}$ & $\begin{array}{c}0.002 \\
(.004)[.0003]\end{array}$ & $\begin{array}{c}0.078 \\
(.0027)[.01]\end{array}$ & $\begin{array}{c}0.01 \\
(.059)[.000]\end{array}$ & $\begin{array}{c}\mathrm{F}(3,717)=2.83 \\
0.0375\end{array}$ \\
\hline $\begin{array}{c}\text { International } \\
\text { shock } \\
\text { ITALY } \\
\end{array}$ & $\begin{array}{c}\mathbf{- 0 . 0 1 4} \\
(.004)[.019]\end{array}$ & $\begin{array}{c}\mathbf{0 . 2 4} \\
(.02)[.010]\end{array}$ & $\begin{array}{c}0.001 \\
(.06)[.000]\end{array}$ & $\begin{array}{c}\mathbf{F ( 3 , 7 1 7 )}=\mathbf{3 6 . 5} \\
\text { Prob }=0.000\end{array}$ \\
\hline $\begin{array}{c}\text { Local Shock } \\
\text { SPAIN }\end{array}$ & $\begin{array}{c}0.0009 \\
(.003)[.0001]\end{array}$ & $\begin{array}{c}-0.0008 \\
(.003)[.0001]\end{array}$ & $\begin{array}{c}\mathbf{- 0 . 1 6} \\
(.049)[.015]\end{array}$ & $\begin{array}{c}\mathbf{F}(3,717)=4.75 \\
\text { Prob }=0.003 \\
\end{array}$ \\
\hline $\begin{array}{l}\text { International } \\
\text { shock } \\
\text { SPAIN }\end{array}$ & $\begin{array}{c}-\mathbf{- 0 . 0 1 3} \\
(.003)[.02]\end{array}$ & $\begin{array}{c}\mathbf{0 . 2 0} \\
(.024)[.09]\end{array}$ & $\begin{array}{c}0.03 \\
(.05)[.0004]\end{array}$ & $\begin{array}{c}\mathbf{F}(\mathbf{3}, \mathbf{7 1 7})=\mathbf{3 4 . 0 7} \\
\text { Prob }=0.000\end{array}$ \\
\hline
\end{tabular}

Innovations in the DM/US\$, in the German Euro $3 \mathrm{~m}$ and in the German 10-year) rate are residuals from a VAR model estimated on these variables for the period Jan93-Sept 95

The variance-covariance matrix of the residuals of such VAR turns out to be diagonal.

The exchange rate is defined as number of DM for one dollar.

Point estimates reported in bold are significant at the five per cent level 


\section{REFERENCES}

Ayuso and Restoy F.(1995) "Interest Rate Parity and Foreign Exchange Risk Premia in the ERM", Paper presented at the CEPR Meeting on "Monetary Policy and Exchange Rates"

Bernanke B.(1986) "Alternative Explanations of the Money-income Correlation", in Brunner-Meltzer eds. Real Business Cycle, Real Exchange Rates and Actual Policies, Carnegie-Rochester Conference Series on Public Policy, 25, Amsterdam, North-Holland, 49-99

Blanchard O.J, and D.Quah(1989) "The Dynamic Effects of Aggregate Demand and supply Disturbances", American Economic Review, 79, 655-73

Cochrane J.(1994) "Permanent and Transitory Components of GNP and Stock Prices", The Quarterly Journal of Economics, 241-267

Cottarelli C. and Mecagni M.(1990) "The Risk Premium on Italian Government Debt, 1976-1988" IMF Working Paper, 90/38,

Doornik J. and Hendry D.F. (1994) PC-GIVE 8.0. An Interactive Econometric Modelling System, Oxford, Institute of Economics and Statistics

Doornik J. and Hendry D.F. (1994) PC-FIML 8.0. Interactive Econometric Modelling of Dynamic Systems, Oxford, Institute of Economics and Statistics

Giannini(1992) Topics in Structural VAR Econometrics, Lecture Notes in Economics and Mathematical Systems, Springer-Verlag

Giannini C.(1992) Cointegrazione, Giornale degli Economisti ed Annali di Economia

Giovannini A. and G. Piga(1994) Understanding the high interest rate on Italian government securities, in Conti Hamaui and Scobie (eds.) Bond markets. Treasury and Debt Management, Chapman and Hall, London

Hansen and T. Sargent(1991) Rational Expectations Econometrics Underground Classics in Economics, Westview Press, San Francisco

Hendry D.F. (1995) Dynamic Econometrics ,Oxford University Press

Johansen S. (1988), Statistical Analysis of Cointegration Vectors, Journal of Economics Dynamics and Control, March.

Johansen S. (1989) Likelihood-based Inference on Cointegration: Theory and Applications, mimeo, University of Copenhagen

Johansen S.(1992) Identifying Restrictions of Linear Equations, University of Copenaghen, Institute of Mathematical Statistics

Johansen S. (1994) Likelihood Based Inference on Cointegration in the Vector Autoregressive Model, Institute of Mathematical Statistics, University of Copenaghen 
Johansen S., Juselius, K. (1990), Maximum Likelihood Estimation and Inference on Cointegration with Applications to the Demand for Money, Oxford Bulletin of Economics and Statistics, May.

Johansen S., Juselius K. (1994), Identification of the Long-run and the Short-Run Structure. An application to the IS-LM model. Journal of Econometrics

Lippi M. and L. Reichlin (1993) "The Dynamic Effects of Aggregate Demand and Supply Disturbances: Comment" American Economic Review, 83, 3, 644-652

Mellander E., Vredin A. e A.Warne (1993) "Stochastic Trends and Economic Fluctuations in a Small Open Economy" Journal of Applied Econometrics

Mosconi R.(1994) "Cointegrazione e Modelli Econometrici: Teoria ed Applicazioni" Metodi quantititativi per la Politica Economica, Banca d'Italia

Osterwald-Lenum M.(1992) "A note with quantiles of the asymptotic distribution of the maximum likelihood cointegration rank test statistics", Oxford Bulletin of Economics and Statistics, 54, 461-472

Pagan A. (1994) "Structural VAR's: a Review" paper presented at the Workshop on Strucutral VAR Modelling, University of Aarhus

Sims C.(1980) "Macroeconomics and Reality", Econometrica, 48, pp.1-48

Svensson L.(1991) “The Simplest Test of Target Zone Credibility”, IMF Staff Papers, 38, 3

Svensson L.(1994) "Estimating and Interpreting Forward Interest Rates: Sweden 1992-1994", Institute for International Economics, Stockholm University 


\section{Appendix: the Moving Average Representation of a Cointegrated VAR model}

To illustrate how a Moving Average representation of a Cointegrated VAR can be derived consider the following general representation of our dynamic system

$$
\begin{aligned}
& \Delta \mathrm{z}_{\mathrm{t}}=A^{*}(L) \Delta \mathrm{z}_{\mathrm{t}-1}+\alpha D R_{\mathrm{t}-1}+B \mathrm{u}_{\mathrm{t}} \\
\text { (A.1) } & z=\left(\begin{array}{l}
S P \\
E R
\end{array}\right)
\end{aligned}
$$

Define then the following vectors and matrices:

$$
\begin{aligned}
& \text { (A.2) } w=\left(\begin{array}{c}
D R \\
S P
\end{array}\right)=\left(\begin{array}{cc}
-1 & 1 \\
0 & 1
\end{array}\right) z_{t}=M z_{t} \\
& \text { (A.3) } x_{t}=\left(\begin{array}{c}
D R \\
\Delta \mathrm{SP}
\end{array}\right)=\left(\begin{array}{cc}
1 & 0 \\
0 & (1-L)
\end{array}\right) w_{t}=D^{-}(L) w_{t} \\
& \text { (A.4) } \Delta w_{t}=D(L) D^{-}(L) w_{t}=\left(\begin{array}{cc}
1-L) & 0 \\
0 & 1
\end{array}\right)\left(\begin{array}{cc}
1 & 0 \\
0 & (1-L)
\end{array}\right) w_{t}
\end{aligned}
$$

Using these results we obtain

$$
\begin{aligned}
& D(L) \boldsymbol{x}_{t}=D(L) D^{-}(L) w_{t}=\Delta \mathbf{w}_{\mathrm{t}} \\
& \Delta \mathbf{w}_{\mathbf{t}}=M \Delta \mathbf{z}_{\mathbf{t}}
\end{aligned}
$$

Substituting from (A.5) into the VECM representation gives the following:

$$
\begin{aligned}
& \left(I-A^{*}(L) L\right) M^{-1} \Delta \mathbf{w}_{\mathrm{t}}=\alpha D R_{t-1}+B u_{t} \\
& \left.\left[\left(I-A^{*}(L) L\right) M^{-1} D(L)+\gamma^{*} L\right)\right] x_{t}=G(L) x_{t}=B u_{t} \\
& \gamma^{*}=\left(\begin{array}{ll}
\alpha & 0 \\
0 & 0
\end{array}\right)
\end{aligned}
$$

Equation (A.7) in Mellander et al.'s(1992) terminology is a restricted VAR. All the variables in (A.7) are integrated of order 0 and we can invert it to find the moving average representation.

In this representation we specify a VAR which features as dependent variables the cointegrating vector and the first differences of the total yield differential:

(A.8) $\Delta S P_{t}=a_{20}+a_{21}(L) D R_{t-1}+a_{22}(L) \Delta S P_{t-1}+b_{21} u_{1 t}+b_{22} u_{2 t}$

$$
\left(\begin{array}{l}
u_{1 t} \\
u_{2 t}
\end{array}\right) \sim N . I . D .(0, I)
$$

Hence we derive impulse response functions with respect to shocks to the exchange rate factor and to the default risk premium. 


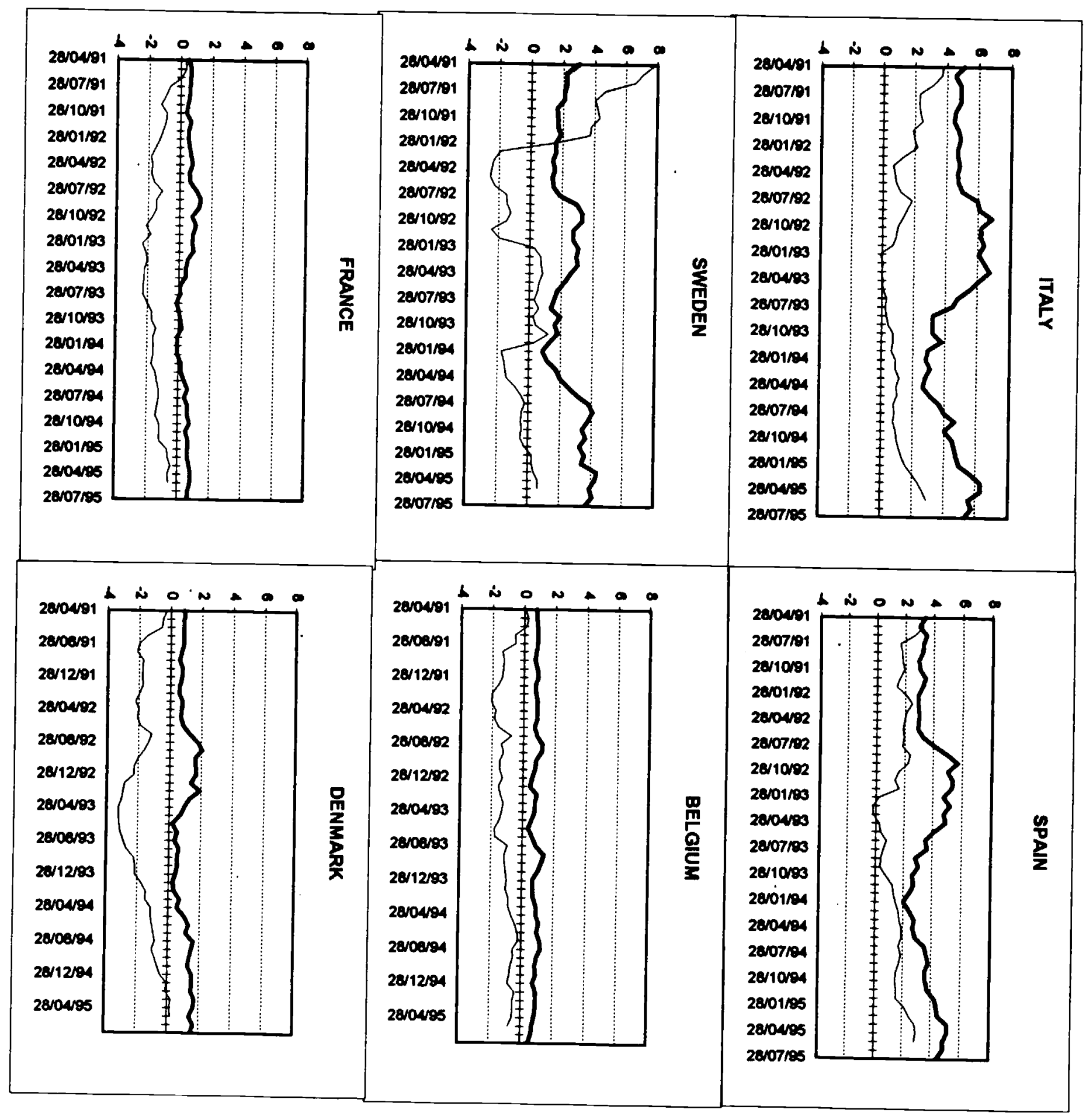

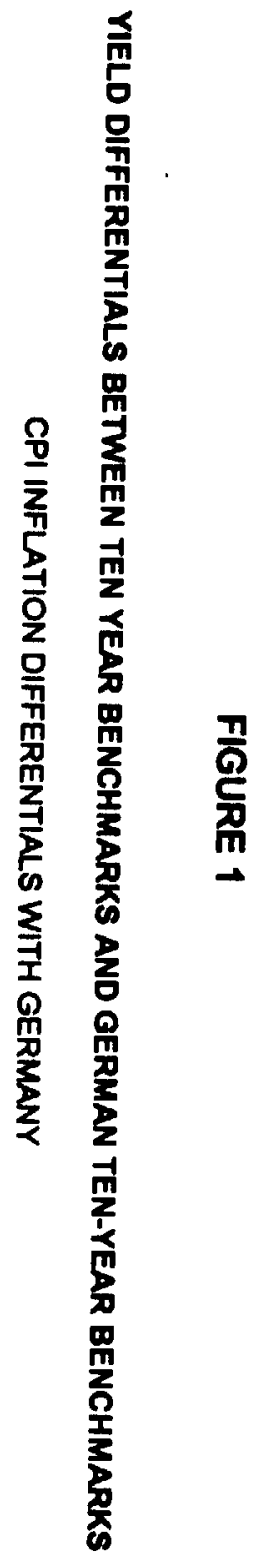


FIGURE 2

MEASURING EXCHANGE RISK: THE CASE OF ITALY

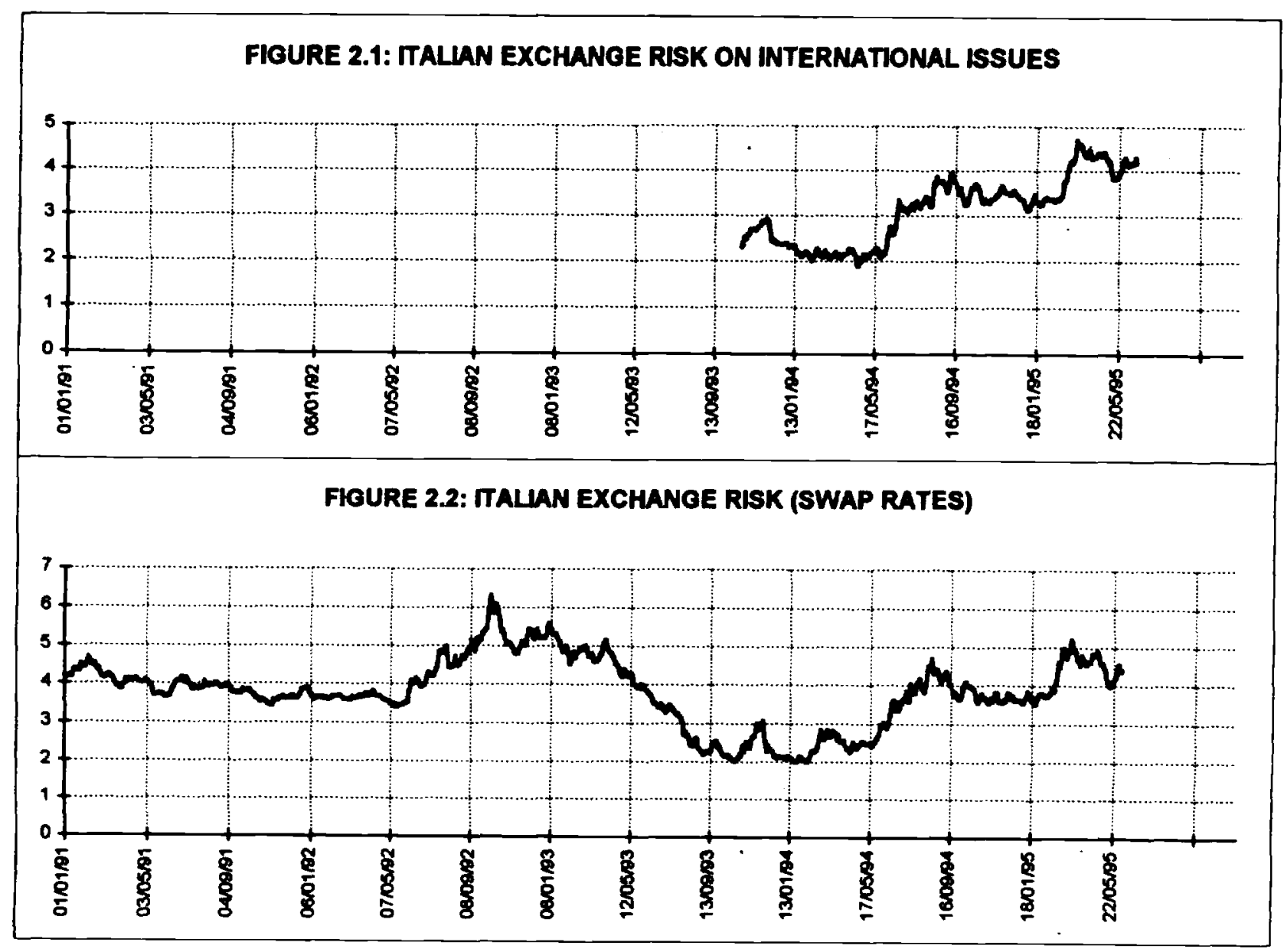

FIGURE 2.1: IBRD 20039.45 LIT - IBRD $200357 / 8$ DM

FIGURE 2.2: ITALIAN LIT 10-YEAR SWAP RATE - D-MARK 10-YEAR SWAP RATE 
MEASURING DEFAULT RISK: THE CASE OF ITALY

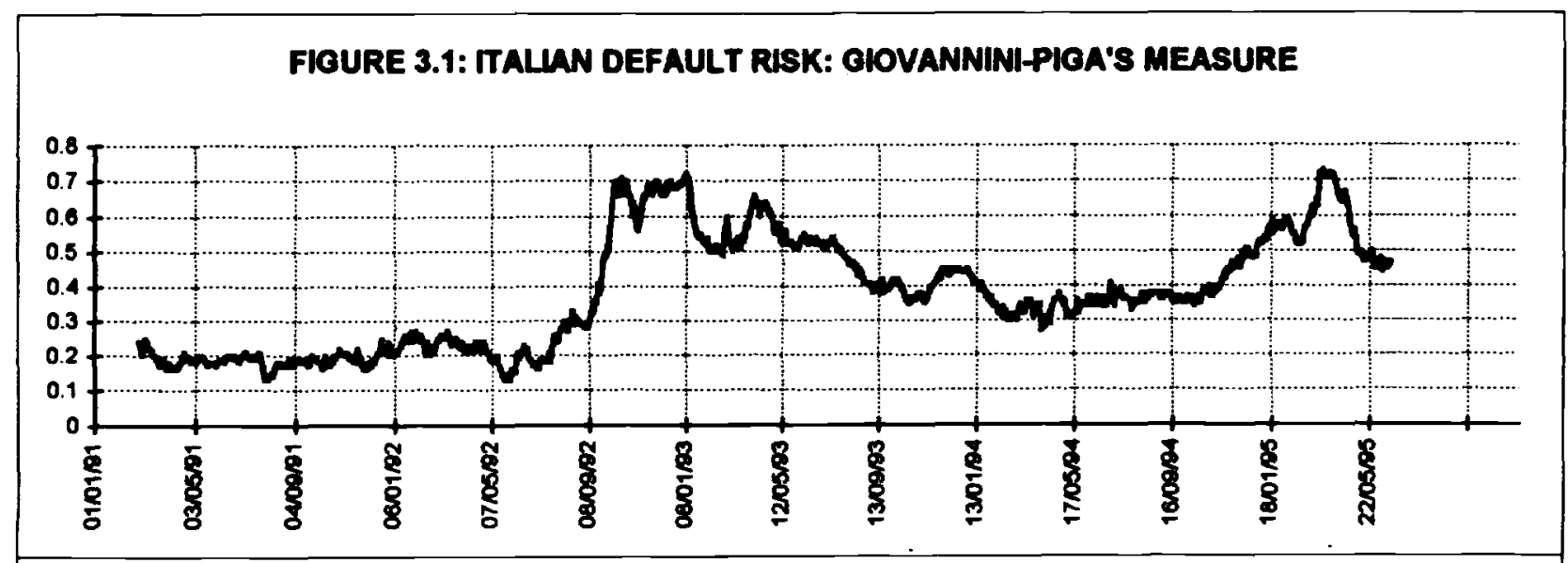

FIGURE 3.2: ITALAN DEFAULT RISK: WORLD BANK ISSUES' BASED MEASURE

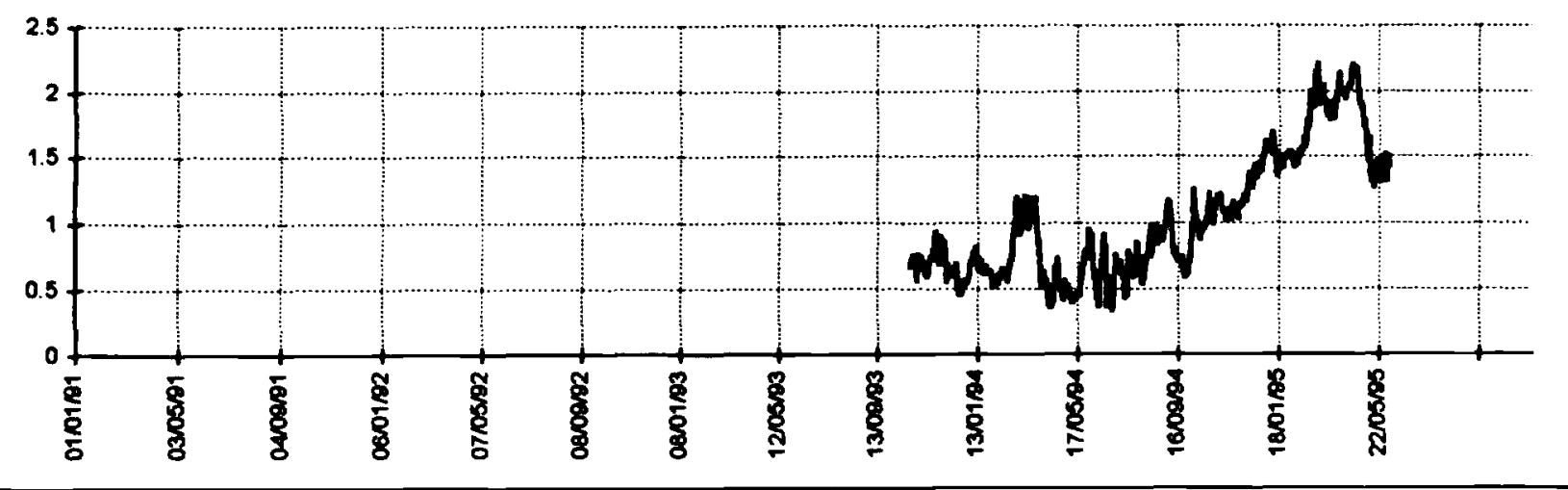

FIGURE 3.3: ITALLN DEFAULT RISK: SWAPS' BASED MEASURE

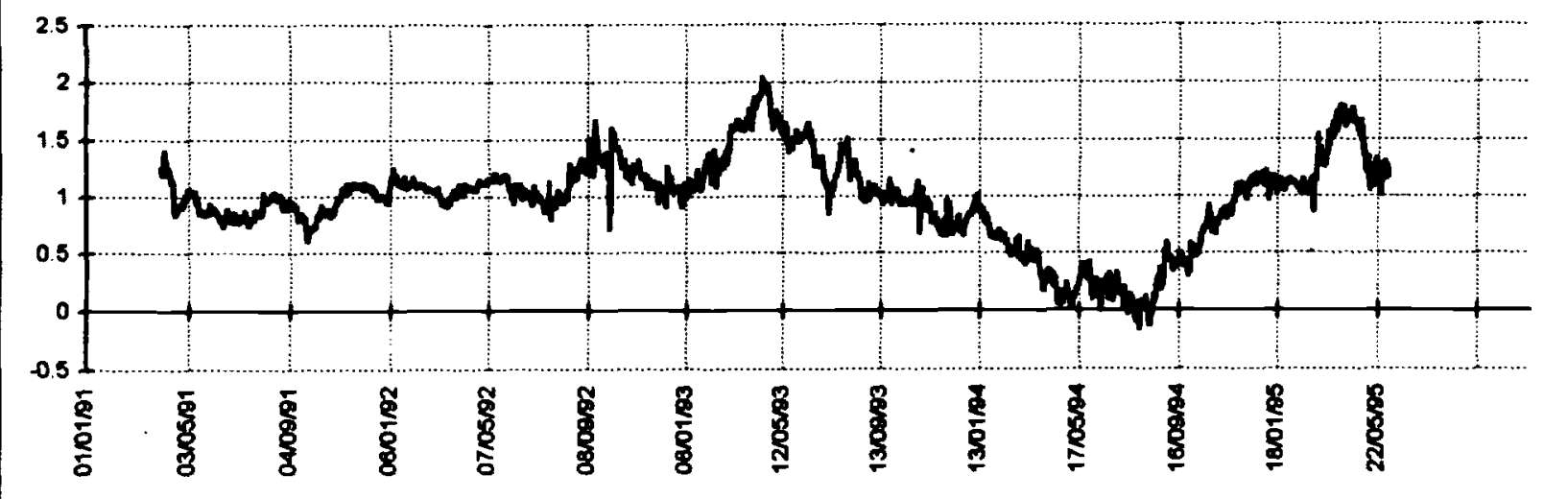

FIGURE 3.1: REPUQLIC OF TALY $200183 / 4$ US - 18RD 20018 1/8 US

FIGURE 3.2: (ITALY BTP 2003 9\% - IBRD 2003 9.45 \% LT) - (BUND 2003 6\% - IBRD $57 \%$ \% 2003 DM)

FIGURE 3.3: (ITALY 10-YEAR BENCHMARK - IT LIT 10-YEAR SWAP) - (GERMANY 10-YEAR BENCHMARK - DM 10-YEAR SWAP) 
FIGURE 4

HIGH YIELDERS

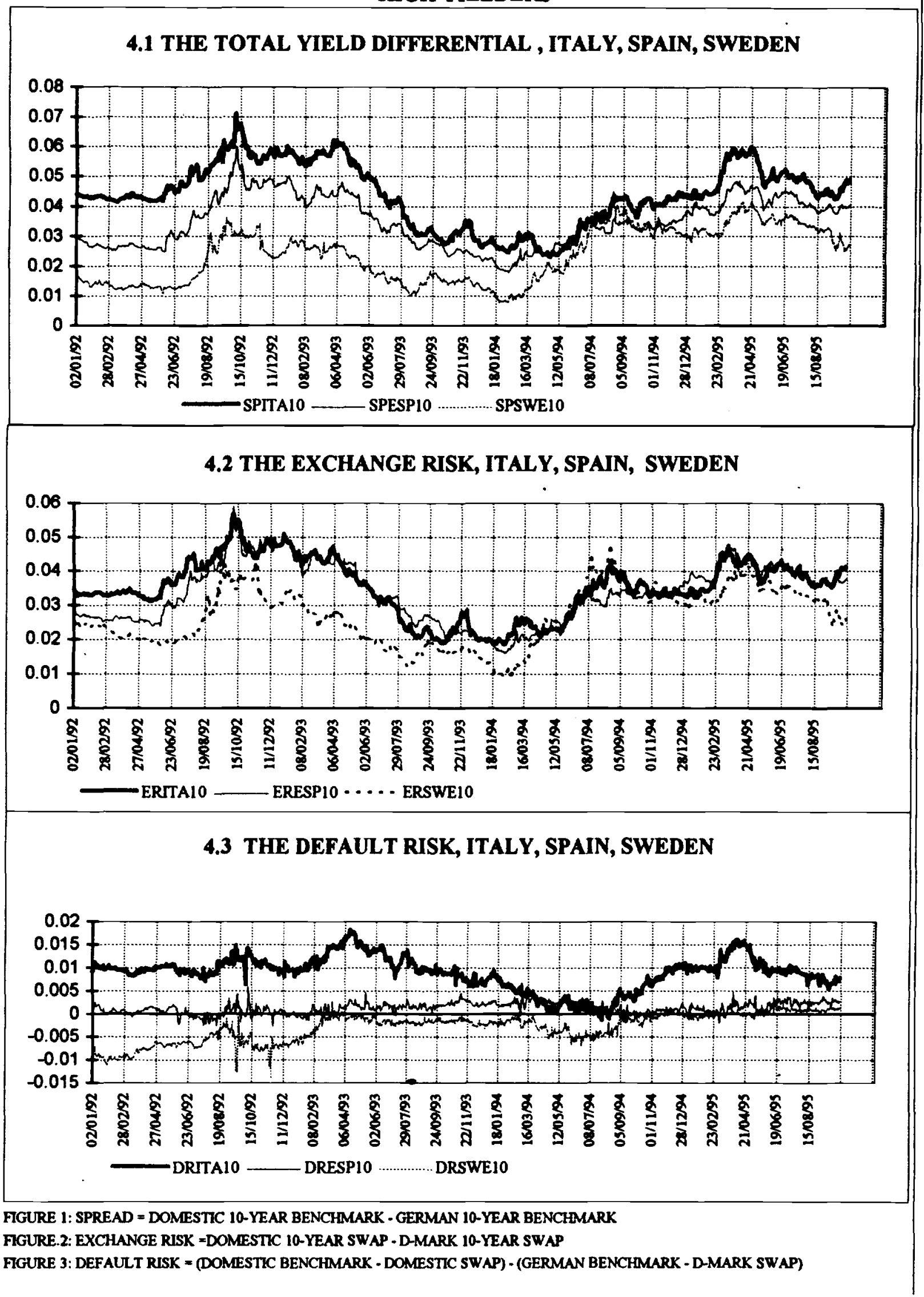




\section{FIGURE 5}

\section{HIGH YIELDERS}

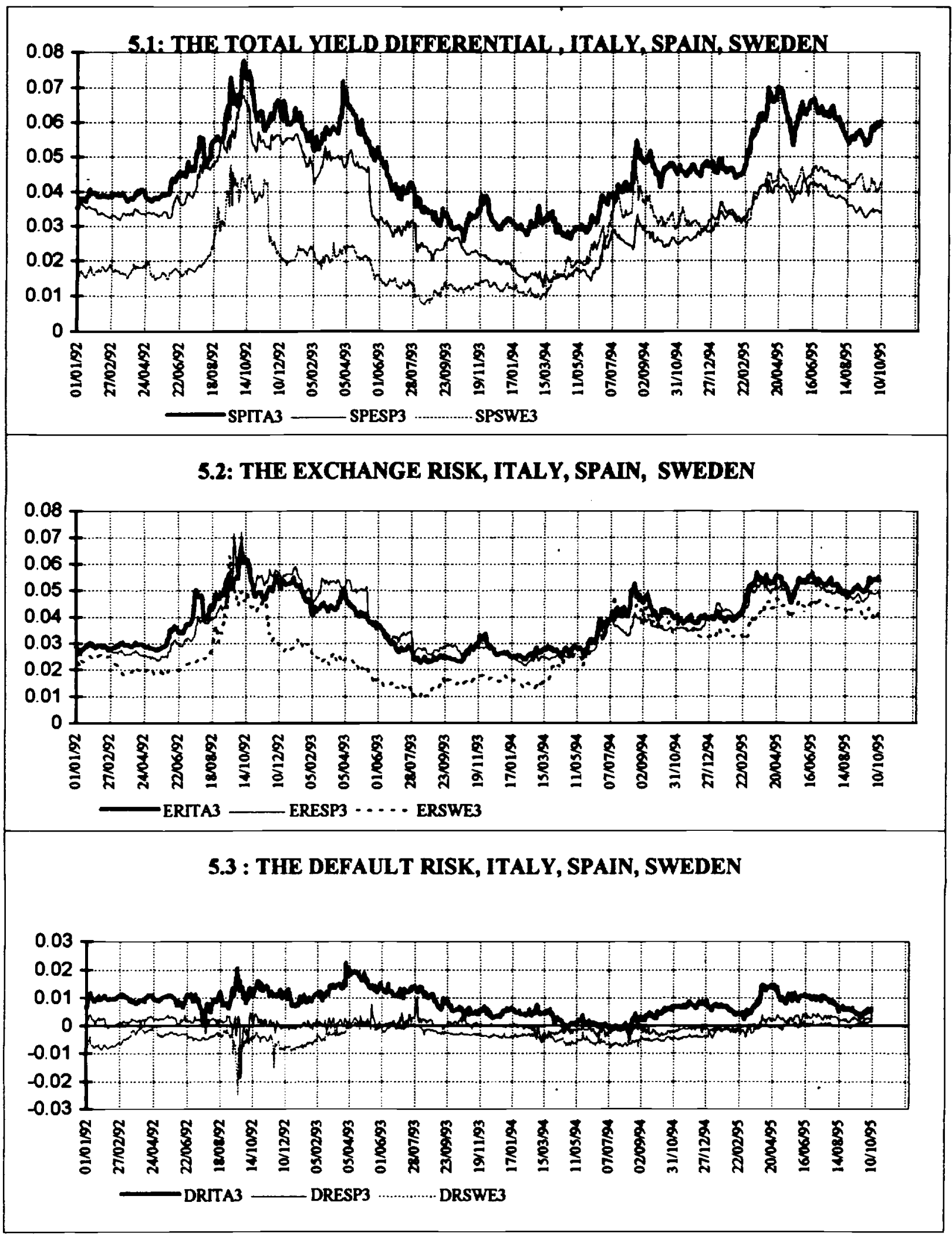

FIGURE 1: SPREAD = DOMESTC 3-YEAR BENCHMARK - GERMAN 3-YEAR BENCHMARK

FIGURE. 2: EXCHANGE RISK =DOMESTIC 3-YEAR SWAP - D-MARK 3-YEAR SWAP

FIGURE 3: DEFAULT RISK = (DOMESTIC BENCHMARK - DOMESTIC SWAP) - (GERMAN BENCHMARK - D-MARK SWAP) 
FIGURE 6

TAXATION AND DEFAULT RISK: THE CASE OF ITALY

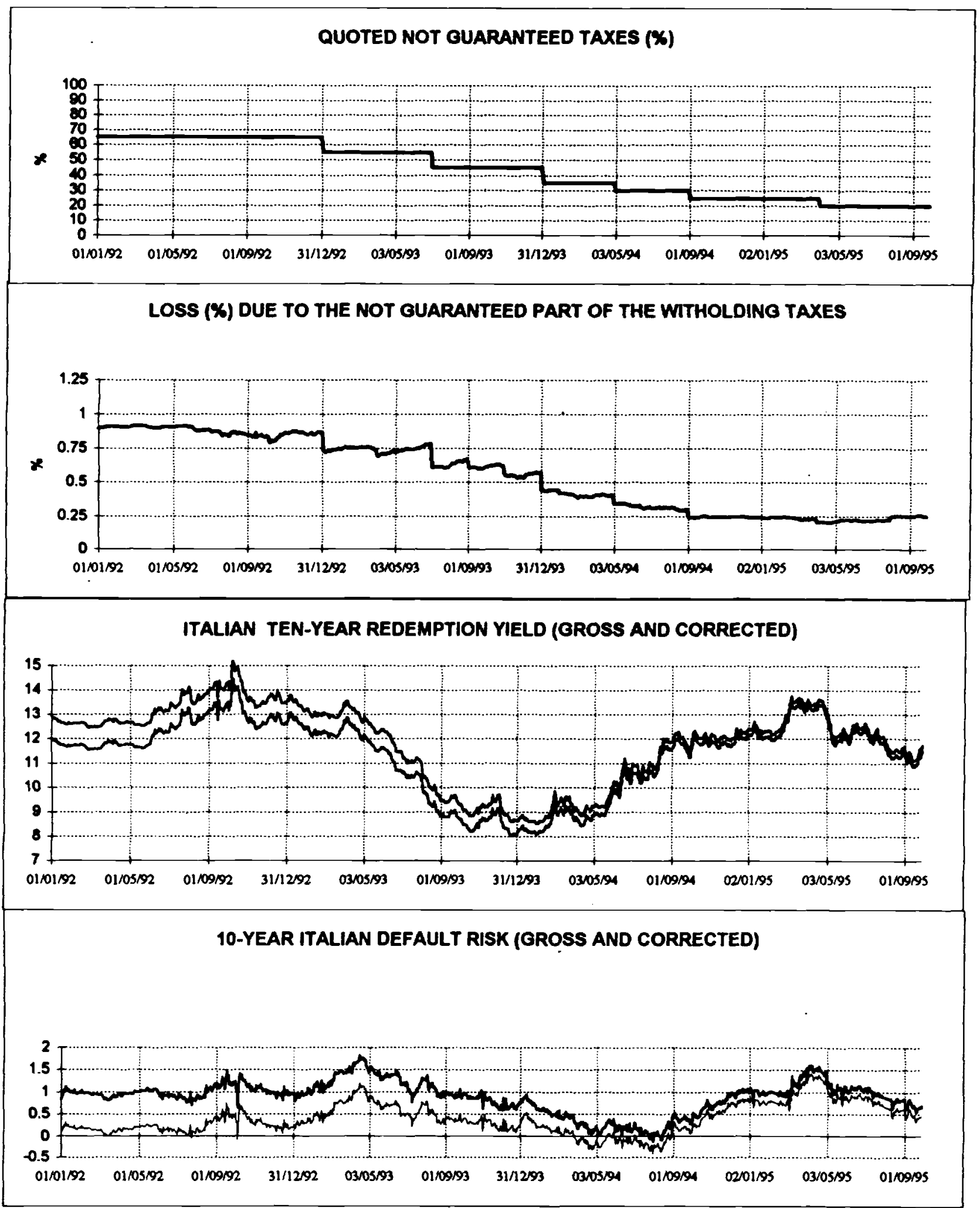

FIGURE 1: THIS FIGURE REPRESENTS THE PERCENTAOE OF THE TAXES ON THB TIALWN BONDS' COUPONS NOT GUARANTEED BY MORGAN STANLEY FIGURE 2: THE LOSS DUE TO THE NOT GUARANTEED PART OF THE WITHOLDNO TAXES HAS BEEN COMPUTED AS THE PRODUCT OF THREE FACTORS: COUPON YIELD • MORGAN STANLEY NOT GUARANTEED TAX (FIGURE 4.1) TAX RATE

FIGURE 3 : THE CORRECTED REDEMPTON YIELD REPRESENTS THE REIEVANT YIEID FOR AN INVESTOR WHO SELLS THE RIGHT TO OBTAN THE REMBBURSEMENT OF THE TAXES TO MORGAN STANLEY

FIGURE 4 : THE GROSS DEFAULT RISK HAS BEEN COMPUTED AS BENCHMARK MINUS SWAP RATE MINUS LIQUITITY PREMIUM ; THE CORRECTED DEF AULT RISK (THIN LNE) IS ADUSTED FOR THE LOSS DUE TO THE NOT GUARANTEED PART OF THE WTTHOLDING TAXES 
FIGURE 7

DIFFERENTIALS BETWEEN ITALIAN AND SPANISH AND MTALIAN AND SWEDISH EXCHANGE FACTORS

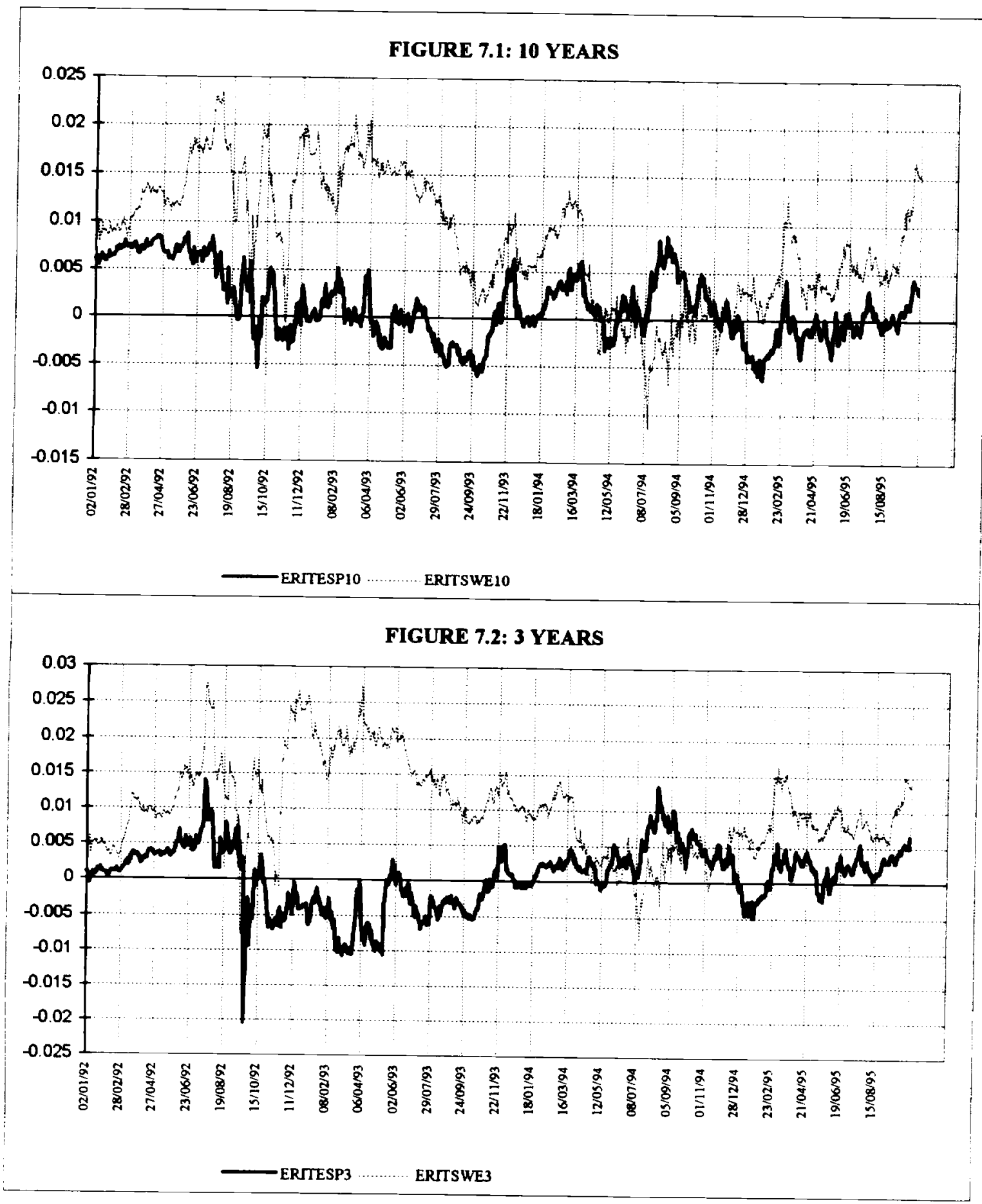

ERITESP=Exchange Premium Italy - Exchange Premium Spain ERITSWE $=$ Exchange Premium Italy - Exchange Premium Sweden 
FIGURE 8

8.1 SPAN:3-YEARS SWAPS' INTEREST RATES (ICESP3) AND CREDIBILITY UPPER BAND (ISPMAX3)

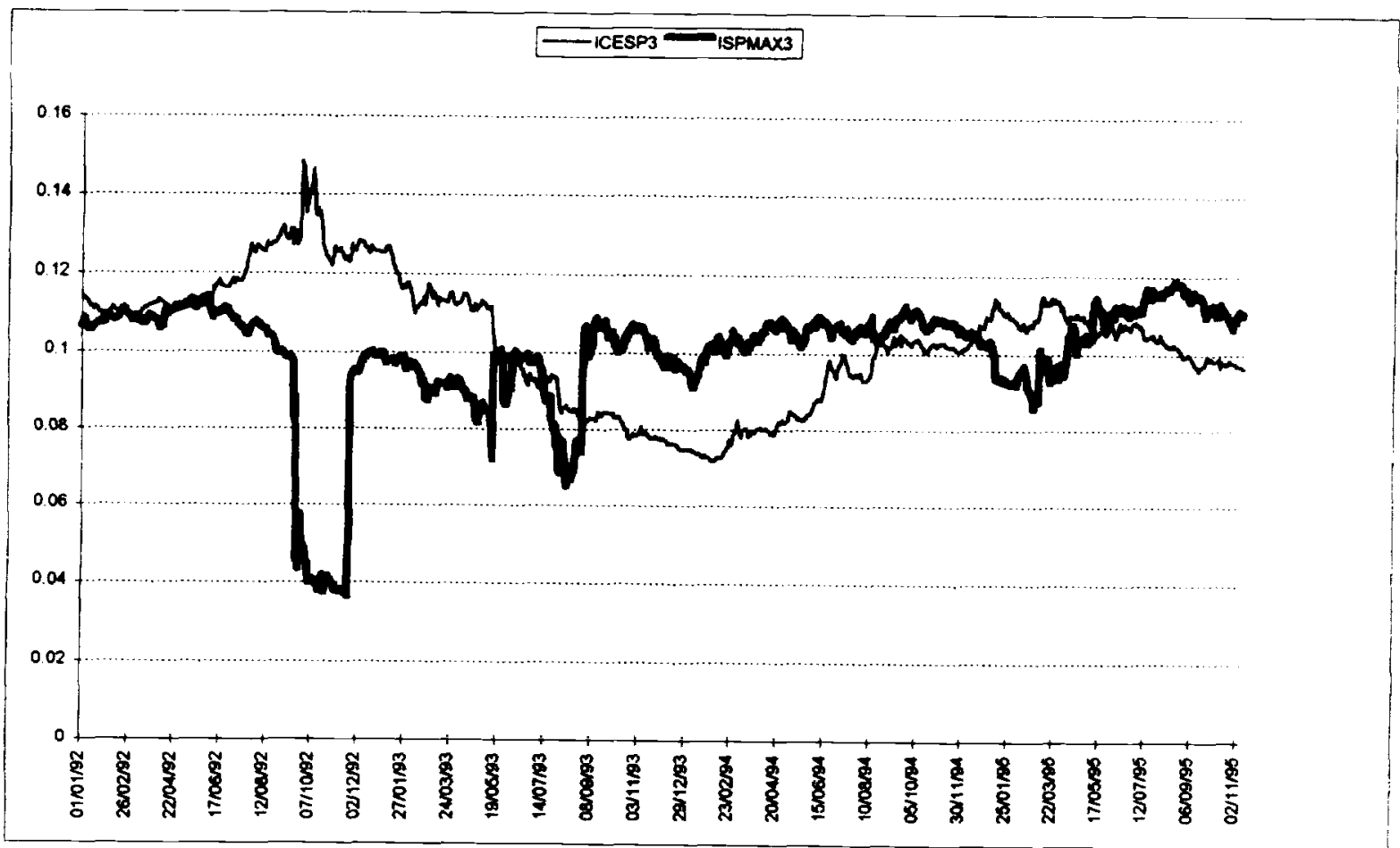

8.1 SPANN:10-YEARS SWAPS' INTEREST RATES (ICESP10) AND CREDIBILITY UPPER BAND (ISPMAX10)

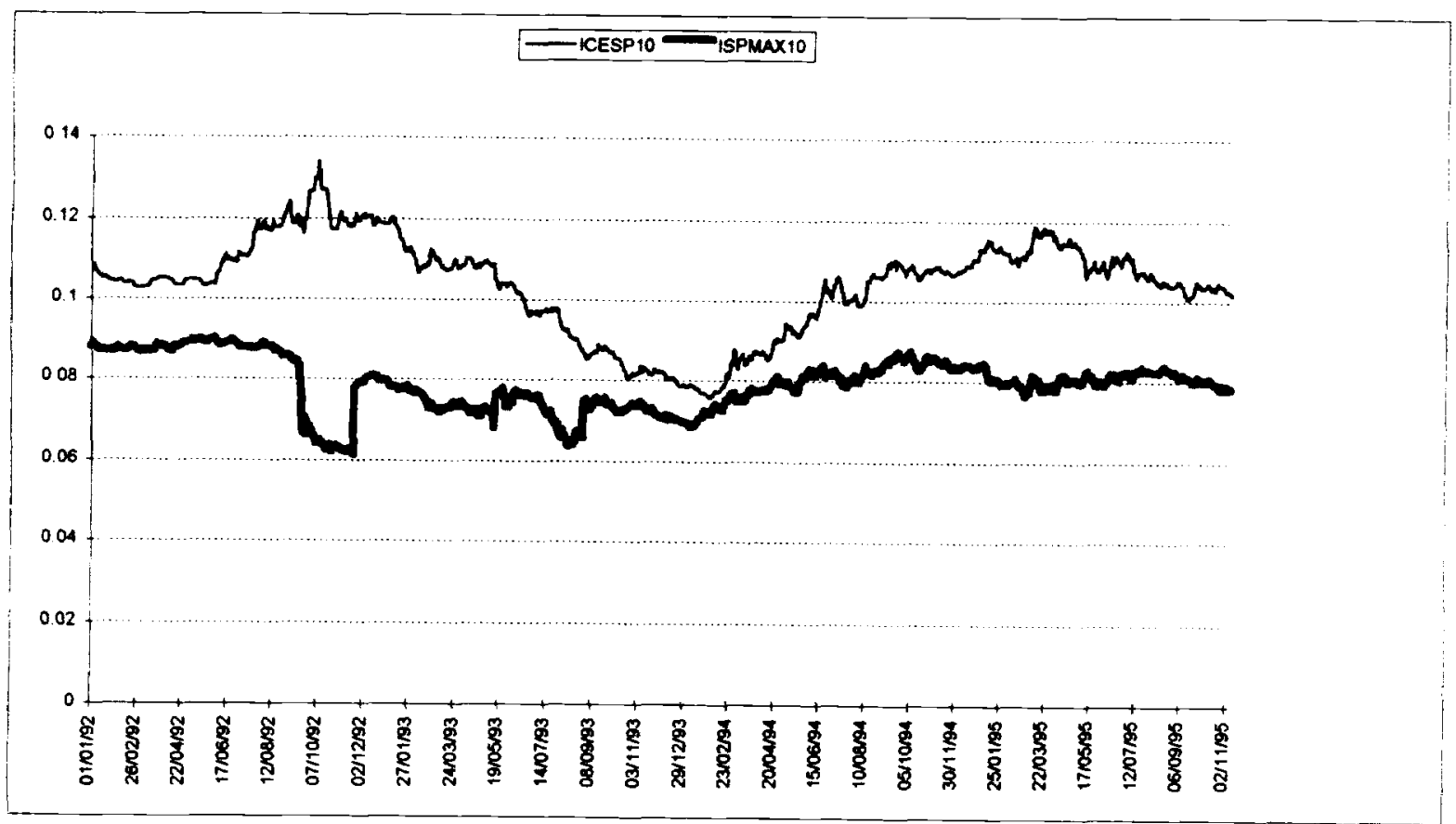



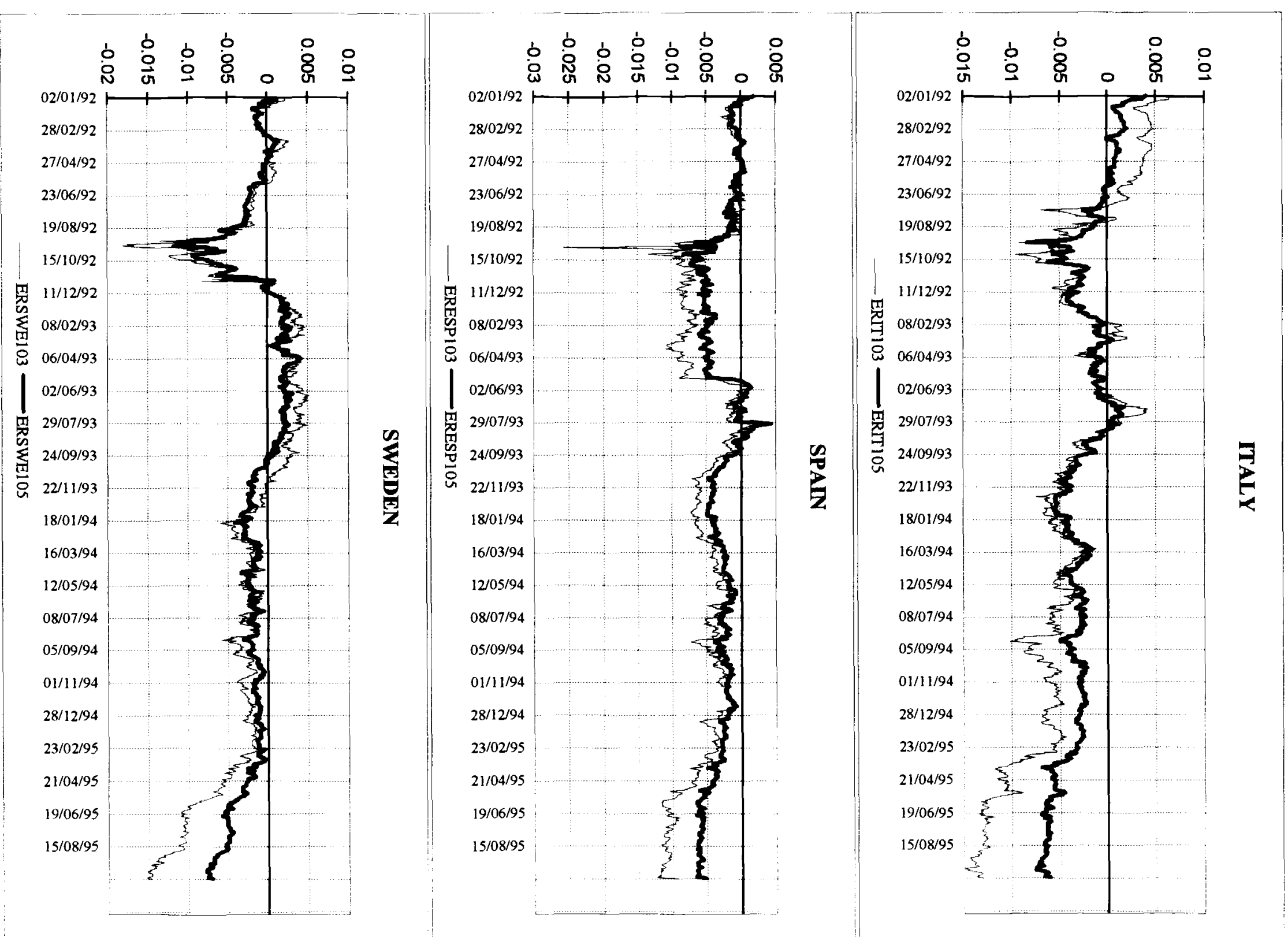

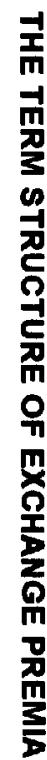


FIGURE 10

THE TERM STRUCTURE OF D-MARK SWAPS INTEREST RATES

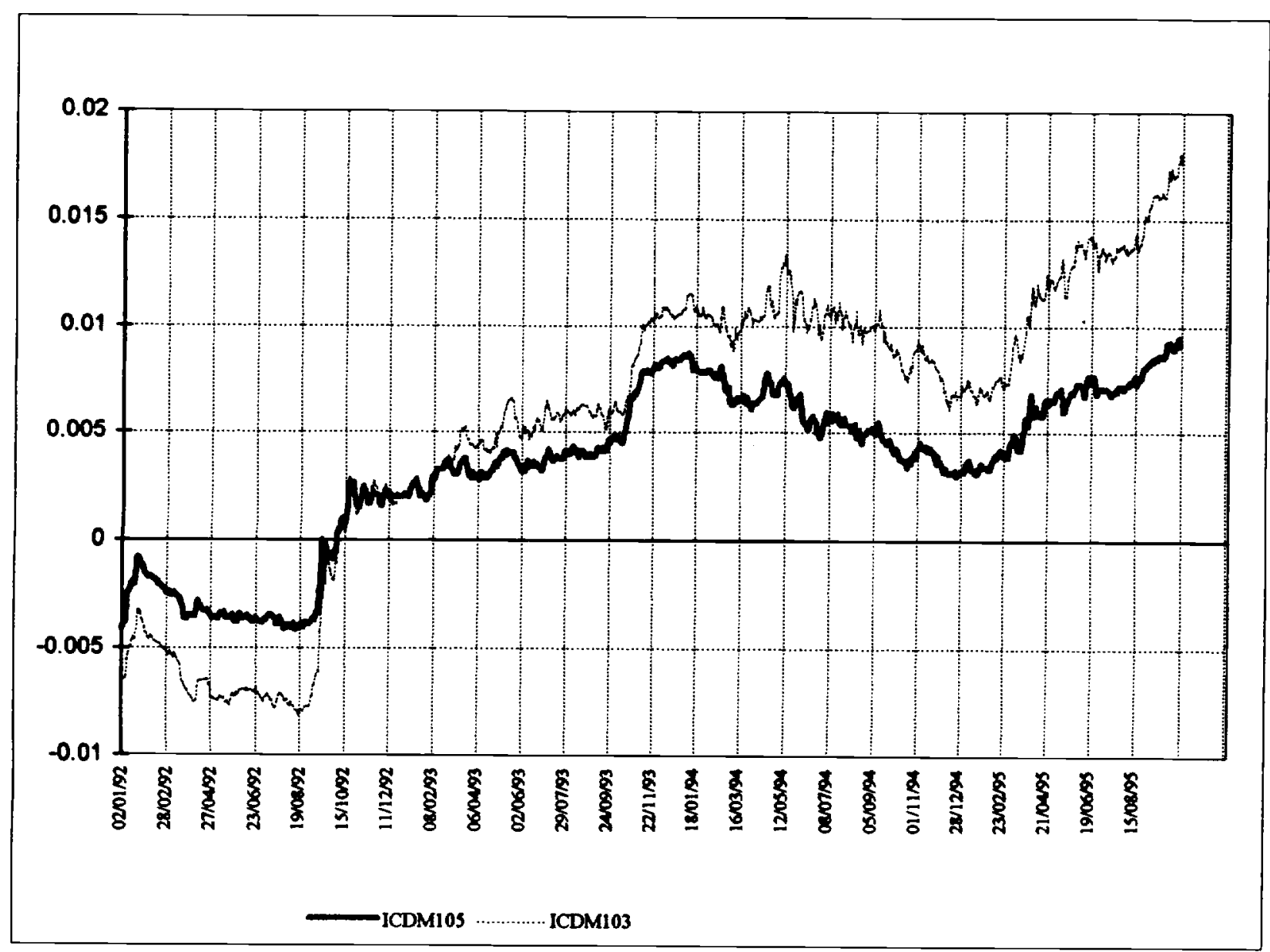

ICDM105= 10-year swap interest rate -5 -year swap interest rate ICDM103 = 10-year swap interest rate - 3-year swrep interest rate All rate continously compounded, denominated in D-marks 


\section{FIGURE 11}

THE TERM STRUCTURE OF DEFAULT PREMIA

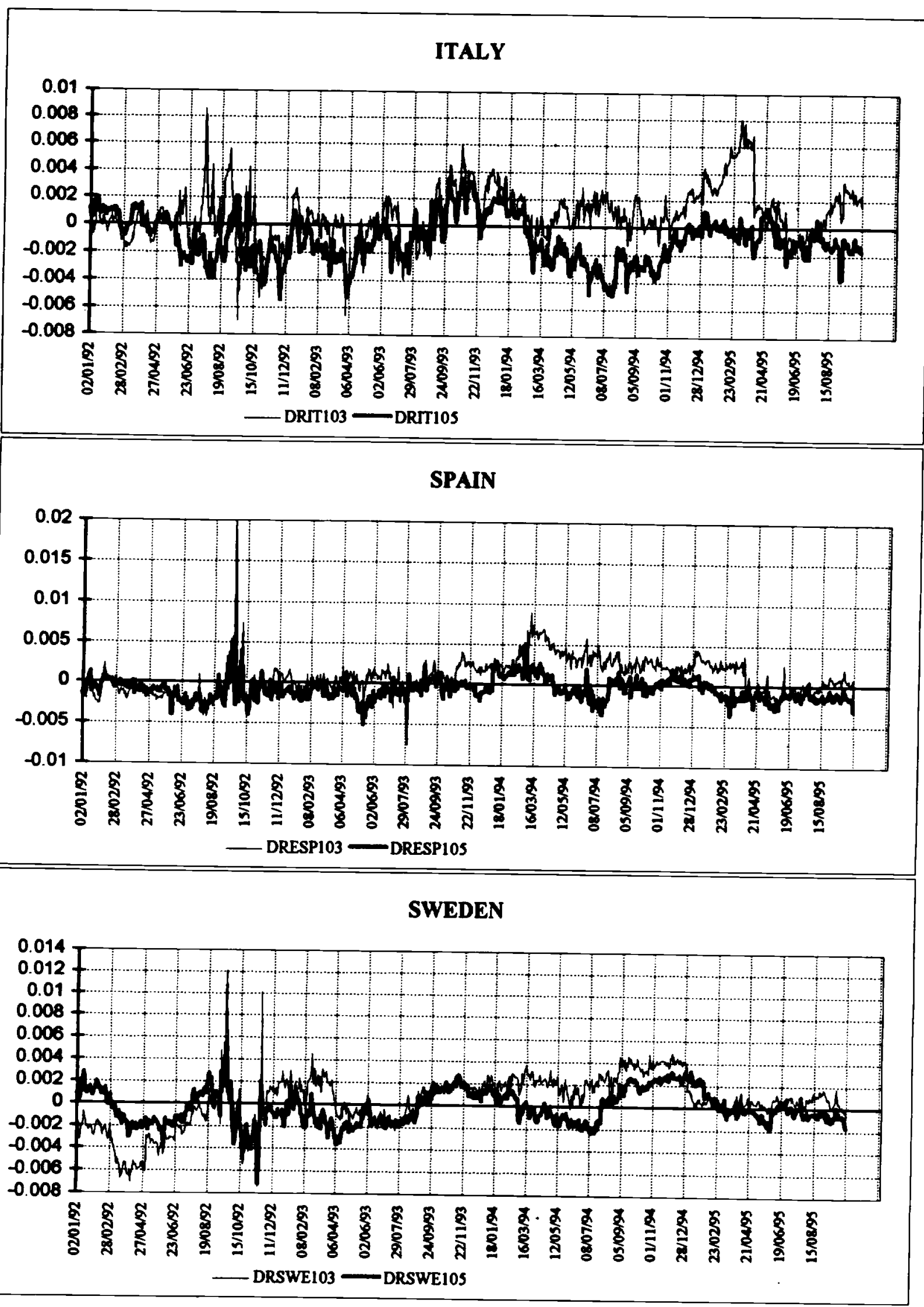


FIGURE 12

THE TERM STRUCTURE OF TOTAL SPREADS

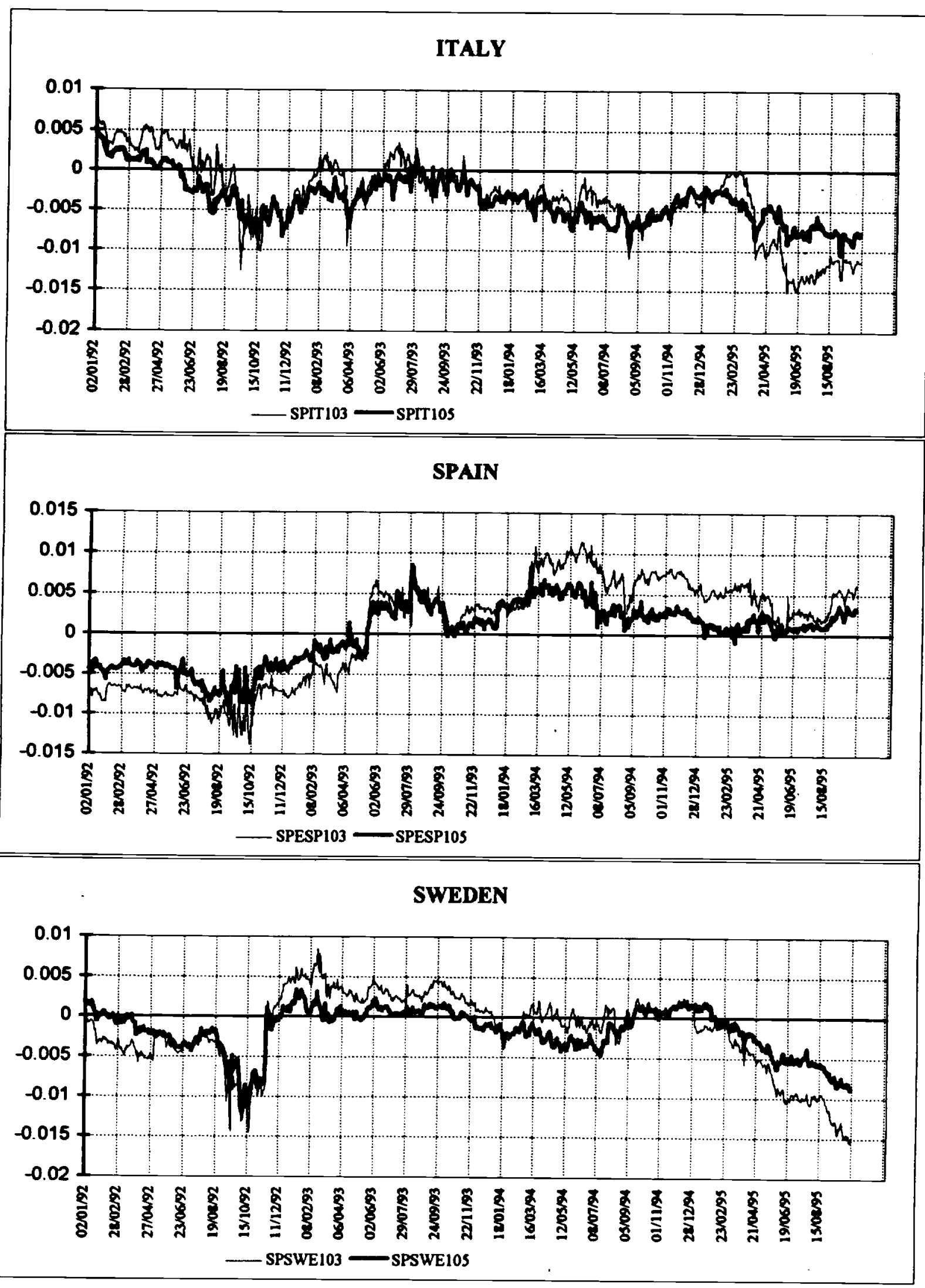




\section{FIGURE 13.1: IMPULSE RESPONSES FOR TTALY}

Responses of the levels of the exchange rate factor and the total yield differential to a one standard deviation international shock and to a one standard deviation country-specific shock. The total yield differential is measured net of the effect of taxation.

Each figure reports point estimates and 95 per cent confidence intervals

Impulse responses should be read as follows:

response of the level of exchange rate factor to international shocks

response of the level of exchange rate factor to country-specific shocks

response of the level of the total spread to international shocks

response of the level of total spread to country specific shocks
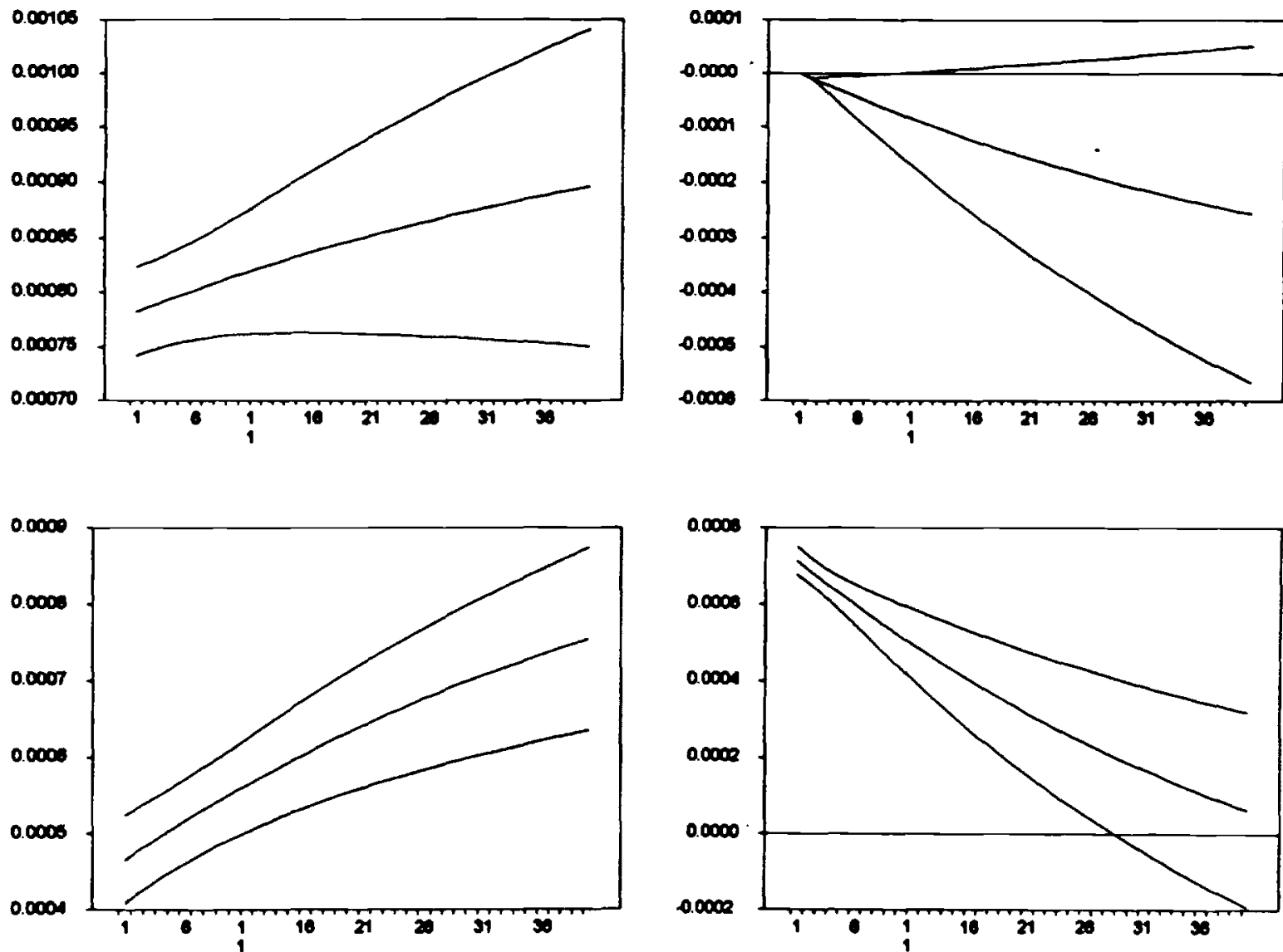


\section{FIGURE 13.2: FORECASTING ERROR VARIANCE DECOMPOSITION FOR ITALY}

Each figure reports the share of forecasting error for the exchange rate factor and the total spreads at different horizons due to the country specific shock and to the international shock

Each figure reports point estimates and 95 per cent confidence intervals

reported figures should be read as follows:

variance of the forecasting error in the exchange rate factor due to international shock variance of the forecasting error in the exchange rate factor due to country-specific shock

variance of the forecasting error in the total spread due to country specific shock
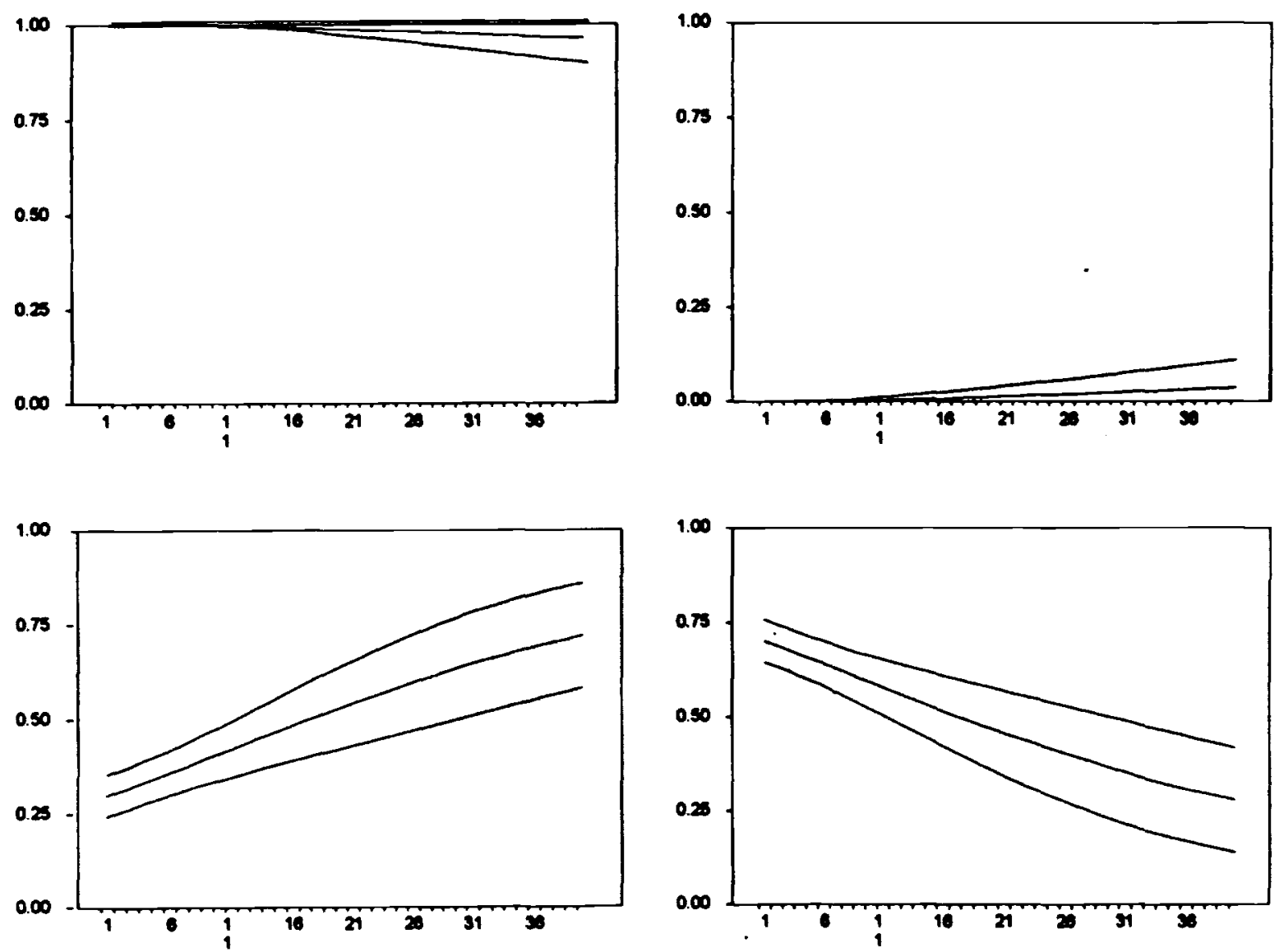


\section{FIGURE 14.1: IMPULSE RESPONSES FOR SPAIN}

Responses of the levels of the exchange rate factor and the total yield differential to a one standard deviation international shock and to a one standard deviation country-specific shock. The total yield differential is measured net of the effect of taxation.

Each figure reports point estimates and 95 per cent confidence intervals

Impulse responses should be read as follows:

response of the level of exchange rate factor to international shocks

response of the level of exchange rate factor to country-specific shocks

response of the level of the total spread to international shocks country specific shocks
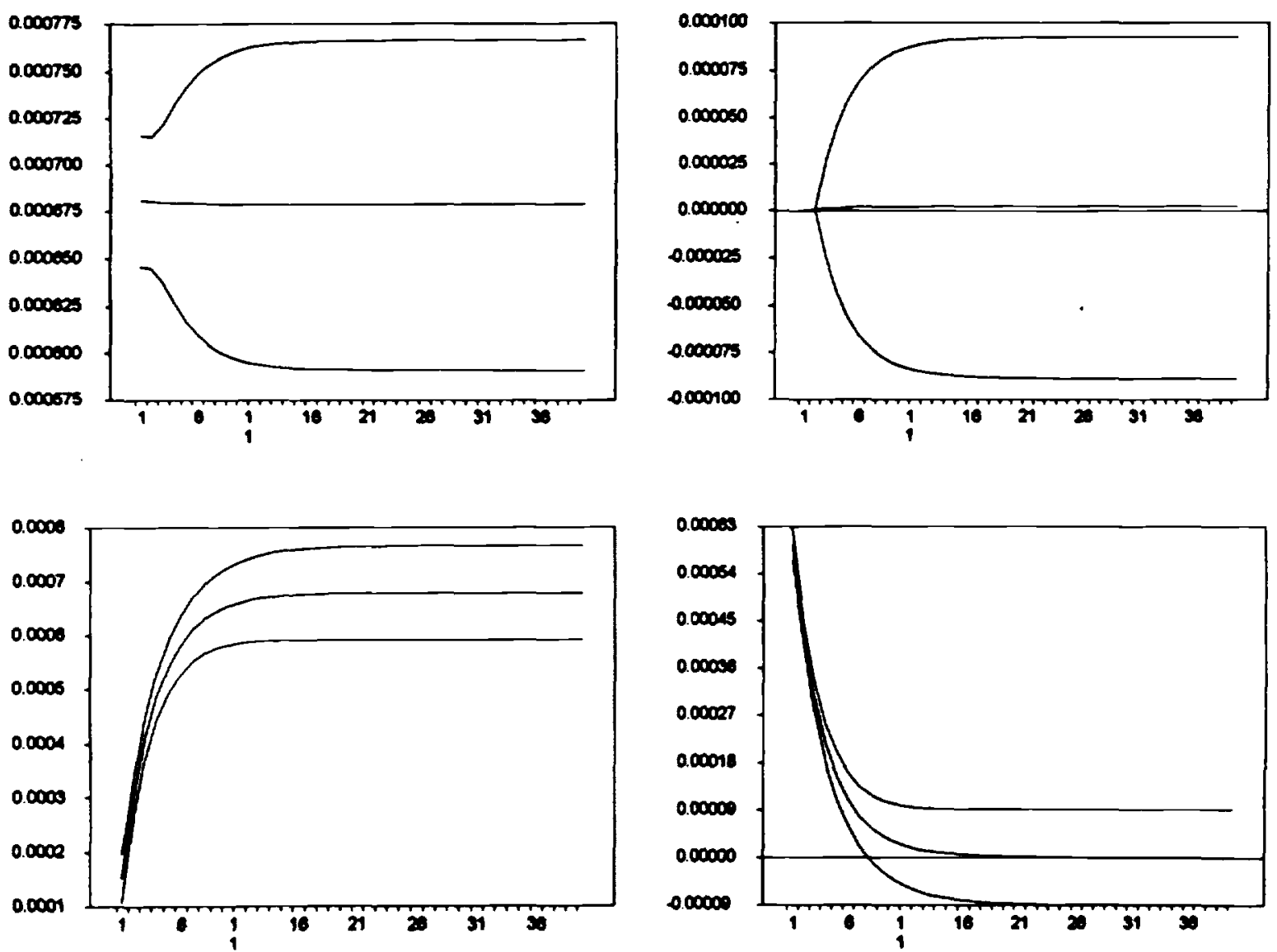
FIGURE 14.2: FORECASTING ERROR VARIANCE DECOMPOSITION FOR SPAIN

Each figure reports the share of forecasting error for the exchange rate factor and the total spreads at different horizons due to the country specific shock and to the international shock

Each figure reports point estimates and 95 per cent confidence intervals

reported figures should be read as follows:

variance of the forecasting error in the exchange rate factor due to international shock

variance of the forecasting error in the total spread due to international shock variance of the forecasting error in the exchange rate factor due to country-specific shock

variance of the forecasting error in the total spread due to country specific shock
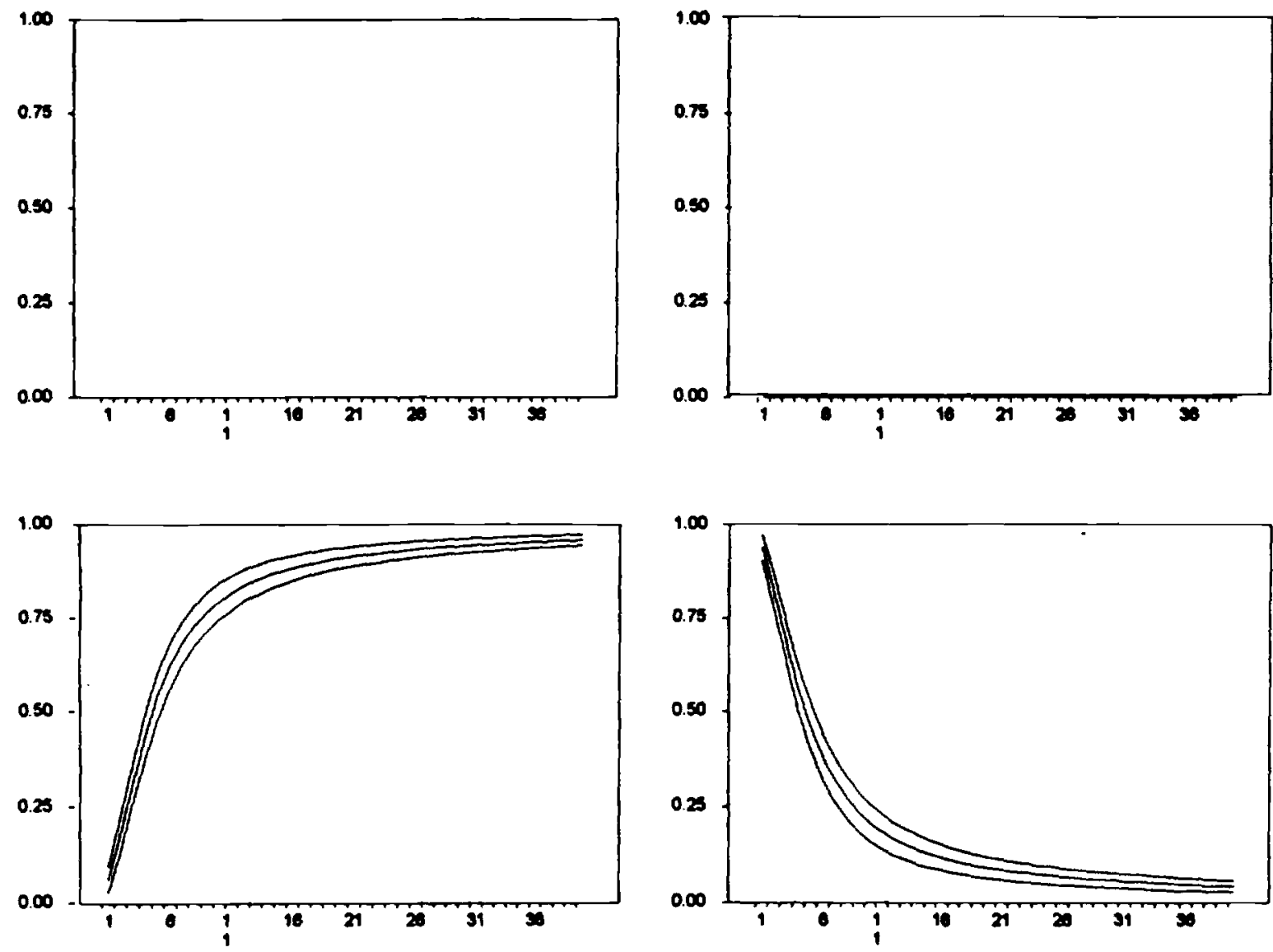